\title{
Do Stock Returns Really Decrease with Default Risk? New International Evidence
}

DOI:

$10.1287 / \mathrm{mnsc} .2016 .2712$

\section{Document Version}

Accepted author manuscript

Link to publication record in Manchester Research Explorer

\section{Citation for published version (APA):}

Aretz, K., Florackis, C., \& Kostakis, A. (2017). Do Stock Returns Really Decrease with Default Risk? New International Evidence. MANAGEMENT SCIENCE, 64(8), 3821-3842. https://doi.org/10.1287/mnsc.2016.2712

\section{Published in:}

MANAGEMENT SCIENCE

\section{Citing this paper}

Please note that where the full-text provided on Manchester Research Explorer is the Author Accepted Manuscript or Proof version this may differ from the final Published version. If citing, it is advised that you check and use the publisher's definitive version.

\section{General rights}

Copyright and moral rights for the publications made accessible in the Research Explorer are retained by the authors and/or other copyright owners and it is a condition of accessing publications that users recognise and abide by the legal requirements associated with these rights.

\section{Takedown policy}

If you believe that this document breaches copyright please refer to the University of Manchester's Takedown Procedures [http://man.ac.uk/04Y6Bo] or contact uml.scholarlycommunications@manchester.ac.uk providing relevant details, so we can investigate your claim.

\section{OPEN ACCESS}




\title{
Do Stock Returns Really Decrease With Default Risk? New International Evidence
}

\author{
Kevin Aretz ${ }^{*}$ Chris Florackis ${ }^{\dagger}$, and Alexandros Kostakis ${ }^{\ddagger}$
}

\begin{abstract}
This study constructs a novel dataset of bankruptcy filings for a large sample of non-US firms in 14 developed markets and sheds new light on the cross-sectional relation between default risk and stock returns. Using the reduced-form approach of Campbell et al. (2008) to estimate default probabilities, we offer conclusive evidence supporting the existence of a significant positive default risk premium in international markets. This finding is robust to different portfolio weighting schemes, data filters, risk-adjusting approaches and holding period definitions. Decomposing the default risk measure into its systematic and idiosyncratic components, we find that the former drives this positive relation. We also show that the default risk premium is more pronounced in countries where creditor protection is stronger and shareholder bargaining power is lower.
\end{abstract}

Keywords: Default risk; Bankruptcy; Stock returns; International financial markets; Creditor protection.

JEL classification: G11, G12, G15.

\footnotetext{
is We would like to thank Amit Seru (Department Editor), an anonymous Associate Editor, and two anonymous referees for insightful suggestions and remarks. We are grateful to Stephen Jones from the University of Sydney, Duane Kennedy from the University of Waterloo, Stephanie Cavanagh from the Office of the Superintendent of Bankruptcy in Canada, Alison Holmes from Duns \& Bradstreet, Heiko Hämäläinen from the Office of the Bankruptcy Ombudsman in Finland, M. Chow from the Hong Kong Company Registrar, Cindy Shirata from the University of Tsukuba, Tokyo, Paul Davey from the Ministry of Economic Development in New Zealand, Christine Albuquerque Correira from the CMVM in Spain, Bruno Ståhl from the Swedish Enforcement Authority, Christine Shao-Wei from the Taiwanese Economic Journal, and Mike Staunton from London Business School for assisting us with collecting the bankruptcy data. We would also like to thank Deniz Anginer, Stefan Arping, Tarik Bazgour, Chris Brooks, Michael Brennan, Nicholas Chen, Jo Danbolt, Campbell Harvey, Jens Hilscher, Torsten Jochem, Andrew Karolyi, Olga Kolokolova, Roman Kräussl, Tomislav Ladika, Maria Marchica, Jocelyn Martel, David McMillan, Mamdouh Medhat, Rajnish Mehra, Maria Michou, Peter Nyberg, Ioannis Oikonomou, Florian Peters, Ilaria Piatti, Joshua Pollet, Peter Pope, Marcel Prokopczuk, Zacharias Sautner, Matti Suominen, Allan Timmermann, Jos van Bommel, Simone Varotto, Christian Wagner, Josef Zechner, conference participants at the 2014 INQUIRE Europe Meeting (Vienna), the 2nd Luxembourg Asset Management Summit, the 11th Corporate Finance Day (Liege), the 2014 Meeting of the European Financial Management Association (Rome), the 2014 Arne Ryde Workshop in Financial Economics (Lund), the 2014 World Finance Conference (Venice), the 19th Annual Conference on Macroeconomic Analysis and International Finance (Crete), the 2015 European Meeting of the Financial Management Association (Venice), and seminar participants at ICMA Centre (Reading), University of Hull, University of Edinburgh, University of Glasgow and University of Amsterdam for helpful comments and suggestions.

* Accounting and Finance Division, Manchester Business School, University of Manchester, Booth Street, Manchester, M15 6PB, UK, tel.: +44 (0) 161275 6368, e-mail: kevin.aretz@manchester.ac.uk.

$\dagger$ Department of Economics, Finance, and Accounting, University of Liverpool Management School, Chatham Street, Liverpool, L69 7ZH, UK, tel.: +44 (0) 151795 53807, e-mail: c.florackis@liverpool.ac.uk.

$\$$ Corresponding author. Accounting and Finance Division, Manchester Business School, University of Manchester, Booth Street, Manchester M15 6PB, UK, tel.: +44 (0) 161275 0434, e-mail: alexandros.kostakis@ manchester.ac.uk.
} 


\section{Introduction}

The cross-sectional relation between default risk and stock returns, the so-called default risk premium, has been a subject of intense debate in the literature. Since the vast majority of defaults occur during recessions (Campbell et al., 2011; Moody's, 2011), that is when investors' marginal utility is high, standard asset pricing theory predicts that highly distressed stocks should yield higher premia relative to less distressed ones. However, most of the prior empirical studies for the US market report a flat, negative, or even hump-shaped relation between stock returns and several well-established proxies for default risk. ${ }^{1}$ Only few recent studies, using either relatively small samples or uncommon proxies for expected stock returns, have reported a significantly positive relation. ${ }^{2}$ The puzzling relation between default risk and stock returns is often called the "distress anomaly".

In a recent insightful study, Gao et al. (2015, hereafter GPS) claim that the literature on the distress anomaly in the US market "[...] is currently characterized by disagreement, both about the basic finding and its interpretation" (p. 1). As a result, GPS argue that it is high time to shift the focus to new data for non-US firms. Using international data over the period 1992-

\footnotetext{
${ }^{1}$ Among the first studies to examine the pricing of default risk is Dichev (1998), who uses Altman's (1968) Z-score and Ohlson's (1980) O-score, showing that these measures are not positively related to stock returns. Similarly, Griffin and Lemmon (2002) use the O-score to show that, after controlling for the book-tomarket ratio, there is no evidence that default risk is priced. More recently, George and Hwang (2010) report a negative relation between stock returns and default risk measured by the O-score after excluding stocks trading at low prices. Departing from the use of accounting models, Vassalou and Xing (2004) extract default risk estimates from the Merton (1974) model and find that a positive return differential exists between stocks with high and low exposures to their default risk measure, but this return differential is significant only for small value firms. Moreover, Da and Gao (2010) show that the premium reported in Vassalou and Xing (2004) is mainly driven by a short-term return reversal effect, and disappears when allowing for a one-month gap between portfolio formation and the beginning of the holding period. Using market-based default probability estimates from the proprietary model of Moody's KMV, Garlappi et al. (2008) and Garlappi and Yan (2011) find a hump-shaped relation between default risk and stock returns, whereas Anginer and Yildizhan (2014) obtain a flat relation between corporate credit spreads and riskadjusted returns. Avramov et al. (2009) show that stock returns significantly increase with S\&P senior debt credit ratings, implying a negative relation between returns and default risk. The most comprehensive evidence comes from Campbell et al. (2008), who measure default risk using a dynamic hazard model. They document a strongly negative relation between default risk and stock returns, which becomes even more significant after accounting for size, value, and momentum premia.

2 Chava and Purnanandam (2010) show that expected stock returns implied from accounting valuation models increase with a broad set of default risk measures. Friewald et al. (2014), using a recent but rather small sample of big US firms, find that stock returns increase with firms' credit risk premia estimated from CDS spreads.
} 
2013, they find a negative relation between stock returns and Moody's KMV Expected Default Frequency (EDF), which becomes more pronounced among small capitalization stocks. GPS fail to find a relation between the default risk premium and creditor protection at the country level, which contradicts the empirical evidence of Garlappi et al. (2008), Garlappi and Yan (2011), and Favara et al. (2012). In contrast, they claim that country-level individualism, which serves as a proxy for investor overconfidence, is significantly negatively related to the default risk premium. Similarly, Eisdorfer et al. (2013, hereafter EGZ) use a default risk proxy derived from the Merton (1974) model (hereafter MDD) to examine the pricing of default risk in an international sample over the period 1992-2010. They find a significant negative MDD-stock return relation, which originates from the developed countries in their dataset.

In the spirit of EGZ and GPS, we also use international data to shed more light on the distress anomaly. However, we do not use a structural model estimate of default risk. Instead, we collect firm bankruptcy filings for 14 developed countries, excluding the US, over the period 1992-2013, and we estimate default probabilities following the reduced-form approach of Campbell et al. (2008, hereafter CHS). Whereas we examine a smaller set of countries than the other two studies, we benefit from the use of a more flexible and better-calibrated default risk proxy. ${ }^{3}$ In particular, our CHS measure incorporates more efficiently cross-country variations with respect to average default rates and the importance of the various default risk indicators; these variations arise from differences in the bankruptcy filing process and are induced by the local bankruptcy laws and institutional settings. Consistent with this conjecture, we show that the parameter estimates of our bankruptcy forecasting model vary significantly across countries.

\footnotetext{
${ }^{3}$ Our dataset features 2.03 million firm-month observations from 14 countries (excluding the US) during the period 1992-2013, in comparison to 4.3 million observations from 38 countries (including the US) in GPS. Despite the lower number of observations, our dataset includes many countries that exhibit relatively low correlations with the US, rendering it suitable for an out-of-sample study (see Foster et al., 1997).
} 
Importantly, in-sample and out-of-sample tests show that the reduced-form approach that we follow in this study exhibits a clearly superior bankruptcy forecasting ability relative to MDD. Adding the CHS default risk indicators to MDD almost doubles the explanatory power of the bankruptcy forecasting LOGIT model in most cases. On the other hand, adding MDD to the CHS default risk indicators typically has a negligible contribution to the model's explanatory power. The CHS measure is also more successful than MDD in classifying as high default risk the firms that subsequently file for bankruptcy. Interestingly, $40 \%$ of all firms that filed for bankruptcy in our sample were ex ante classified into the $5^{\text {th }}$ highest default risk percentile according to CHS, whereas the corresponding portion of bankruptcies classified into the $5^{\text {th }}$ highest percentile according to MDD is only $30.8 \%$. These results confirm, for the first time in an international setup, the superiority of the reduced-form approach reported for US firms by Campbell et al. (2008), and echo the conclusion of Bharath and Shumway (2008) that MDD is not a sufficient statistic for bankruptcy forecasting. ${ }^{4}$

Our asset pricing results are notably different from those in EGZ and GPS. We estimate country-specific LOGIT models to compute out-of-sample (OOS) default probabilities for firms in Australia, Canada, France, Germany, Japan, and the UK (hereafter, the C6 countries) over the sample period 2000-2014. Taking the perspective of an international investor, we use the entire cross-section of these estimated default probabilities to sort stocks into international portfolios and to compute their post-ranking returns. We find an economically and statistically significant positive relation between default risk and stock returns. In particular, the spread strategy that is long the highest default risk quintile portfolio and short the lowest one yields an average return of $13.86 \%$ p.a. (t-stat: 2.71$)$ in the case of value-weighted portfolios and $10.24 \%$ p.a. (t-stat: 2.43 ) in the case of equally-weighted portfolios. Next, we estimate bankruptcy regime-specific LOGIT models to compute OOS default probabilities for firms in

\footnotetext{
${ }^{4}$ Bharath and Shumway (2008) and Campbell et al. (2008) show that hazard model estimates are superior in forecasting US firm defaults as compared to structural estimates obtained from the Merton (1974) model (MDD) and calculated using either the Hillegeist et al. (2004) or the Vassalou and Xing (2004) methodology. We are unaware of any prior study testing the forecasting ability of CHS and MDD for non-US firms.
} 
countries with too few bankruptcies to estimate country-specific LOGIT models (Denmark, Finland, Hong Kong, New Zealand, Portugal, Spain, Sweden, and Taiwan). Using the OOS default probabilities from these eight countries together with the ones from the C6 countries (hereafter, the $\mathrm{C} 14$ countries), we obtain very similar conclusions. ${ }^{5}$

Adjusting for market risk does not materially affect these findings. However, adjusting for size and value premia, the magnitude of the default risk premium is reduced in the case of value-weighted portfolio returns, suggesting that, in line with the conjectures of Chan and Chen (1991) and Fama and French (1996), and the evidence in Vassalou and Xing (2004), the latter factors are related to default risk. Nevertheless, the default risk premium remains significant. Moreover, in line with the arguments of Kapadia (2011), the returns of the market, size, and value factors are negatively correlated with contemporaneous innovations in aggregate default risk, whereas the market and size factor returns also contain predictive ability with respect to future changes in firms' failure rates.

Why do our results differ from those in EGZ and GPS ${ }^{6}$ To address this question, we compare our CHS estimates with the corresponding MDD estimates. MDD is thought to be a close proxy for EDF (Bharath and Shumway, 2008; Correia et al., 2012). Also, in contrast to EDF, which is proprietary, MDD is replicable for our international sample. Equipped with CHS and MDD, we repeat the portfolio formation exercises using each of the two measures as

\footnotetext{
${ }^{5}$ For comparison, we also examine the CHS default risk-stock return relation in the US market during our sample period. To this end, we combine the OOS LOGIT model estimates obtained by Campbell et al. (2008) with the LOGIT model's predictor variables constructed from CRSP and COMPUSTAT data following exactly the same procedures as they do. Consistent with their remark that "the outperformance of the portfolio that is long safe stocks and short distressed stocks is concentrated in periods such as the late 1980s" (p. 2928), and the evidence provided in O'Doherty (2012), the asset pricing tests presented in the Supplementary Appendix show that the default risk-stock return relation has become insignificant post2000. Nevertheless, we still fail to find the theoretically expected positive relation. Thus, the different conclusions that we derive from our international sample relative to the puzzling evidence documented in the literature for US firms are not solely driven by the fact that we consider a more recent sample period. We are grateful to Jens Hilscher for providing their OOS LOGIT model estimates.

${ }^{6}$ In particular, GPS find that, outside the US market, an equally-weighted spread strategy, which is long low default risk stocks and short high default risk stocks, yields an abnormal performance of around 30 basis points per month. This abnormal performance becomes stronger among small capitalization firms. Moreover, EGZ find that, in developed markets, value-weighted portfolios of stocks in the most distressed quintile underperform the corresponding portfolios of stocks in the least distressed quintile by an average of 17 to 63 basis points per month.
} 
alternative sorting criteria only for those firm-month observations for which both measures are available. Whereas CHS still yields a positive default risk premium, MDD yields a Ushape relation. In particular, for the C6 countries, the spread strategy Q5-Q1 that is long the highest MDD quintile portfolio (Q5) and short the lowest one (Q1) yields an insignificant value-weighted (equally-weighted) premium of $1.21 \%(-0.86 \%)$ p.a..

Examining the source of discrepancy between CHS and MDD, we find that these two measures considerably disagree on the identification of low default risk firms. In particular, out-of-sample bankruptcy forecasting tests show that CHS is also superior to MDD in identifying low default risk firms. Computing the frequency of actual bankruptcies across portfolios constructed on the basis of each of these two measures, we find that the proportion of filings by firms classified into the lowest MDD default risk quintile is twice as high as the corresponding proportion of firms classified into the lowest CHS quintile.

This disagreement is driven by unlevered firms as well as default-triggering events ignored by MDD, but not by CHS. Whereas MDD assigns zero default risk to unlevered firms because it assumes that default occurs only if the asset value drops below a fraction of the debt value (see Crosbie and Bohn, 2003; Vassalou and Xing, 2004), CHS assigns a higher default risk to such firms. Moreover, Davydenko (2008) shows that whereas most defaulting firms are insolvent and illiquid, a fraction of them are only illiquid. Similar to the MDD proxy used by EGZ, the EDF proxy used by GPS also abstracts from bankruptcies triggered by liquidity issues, whereas the CHS proxy takes them into account.

In further analysis, we examine what drives the documented positive default risk premium. To this end, we construct double-sorted portfolios on CHS and a series of country-level characteristics. Overall, the premium is found to be relatively higher in countries where creditor protection is higher and shareholder bargaining power is lower, in line with the arguments of Favara et al. (2012). Moreover, consistent with the shareholder advantage hypothesis of Garlappi et al. (2008) and Garlappi and Yan (2011), we find that the default risk premium is 
more pronounced among firms with high asset tangibility. ${ }^{7}$ To the contrary, we do not find any evidence that the default risk premium is driven by investor overconfidence, stock market liquidity conditions or the quality of accounting standards at the country level.

Finally, following Anginer and Yildizhan (2014), we decompose the CHS default risk measure into its systematic and idiosyncratic components. Consistent with the arguments of Anginer and Yildizhan (2014), Friewald et al. (2014), and Hilscher and Wilson (2015), we find that it is the systematic component of firm default risk that drives the positive relation between default risk and stock premia. On the other hand, the idiosyncratic component of default risk yields an insignificant relation.

\section{Data}

\subsection{Bankruptcy Data}

Our sources for the bankruptcy filing data are provided in the Supplementary Appendix. These sources include commercial data providers, government institutions, stock exchanges, and other researchers. In a number of cases, we have merged data from more than one source to extend the length of the sample period. For most countries, the data cover the period from January 1996 to December 2013, although for France, Japan, and the UK they begin slightly earlier (1992-1993). The data contain, at the very least, the identity of the filing firm and the filing date. The dataset includes filings under any legal procedure, except where noted. Since we often lack information on how long firms spent in re-organization, we drop firms after their initial bankruptcy filing in our sample period.

\footnotetext{
${ }^{7}$ Garlappi et al. (2008) and Garlappi and Yan (2011) show that, if shareholders possess high bargaining power relative to creditors, then the former can strategically default to extract rents from the latter. Distressed firms in which shareholder bargaining power is high are less risky for shareholders, and hence they do not yield a premium. This argument is reinforced by the evidence of Hackbarth et al. (2015), who use the 1978 US Bankruptcy Reform Act as a natural experiment of shifting bargaining power towards shareholders. Along the same lines, Favara et al. (2012) show that equity risk is lower in countries with bankruptcy procedures that favor debt renegotiations and with low creditor recovery rate.
} 
Table 1 reports the number of bankruptcy filings, the number of firms with complete data, and the proportion of bankruptcy filings per country and year. To save space, filings and descriptive statistics are reported only for the C6 countries. This is the most comprehensive bankruptcy dataset for non-US firms that has been examined in the literature, containing 944 bankruptcies across 14 developed markets. Table 1 shows that the frequency of bankruptcy filings considerably varies across countries. Filings are more frequent in countries where the bankruptcy system strongly favors managers or creditors (Germany and the UK) relative to countries where employee welfare is more important (France and Japan). In addition, bankruptcy filings are strongly correlated through time, reaching a peak in the aftermath of the 2007-2008 global financial crisis.

[Table 1 here]

Since we require a sufficient number of filings for model estimation and calculation of default probabilities, we recursively estimate our LOGIT models starting from December 1999; hence we perform our OOS asset pricing tests for the period 2000-2014. This choice ensures that there are at least five bankruptcy filings for each country for which we separately run LOGIT models (i.e., the C6 countries) before the start of the test period.

\subsection{Default Risk Indicators}

We use the same default risk indicators as in Campbell et al. (2008) to estimate default probabilities. The first variable is the ratio of net income to a market value-adjusted version of total assets (NIMTA), where the latter is defined as the market value of equity plus the book value of total liabilities. Similar to Campbell et al. (2008), we use the market, instead of the book value of equity in the denominator of NIMTA, because the former captures firms' prospects more accurately. Leverage is measured using the ratio of total liabilities to the market value- 
adjusted version of total assets (TLMTA) ${ }^{8}$ Since lack of liquidity can also force a firm to file for bankruptcy (Davydenko, 2008), we proxy internal cash by the ratio of cash holdings plus short-term assets to the market value-adjusted version of total assets (CASHMTA). Moreover, we use the market-to-book ratio (MB) to measure growth opportunities. ${ }^{9}$

We also utilize market-based default risk indicators, such as the firm's monthly log stock return in excess of the index return of the market in which the firm is headquartered (EXRET), and the annualized standard deviation of the firm's daily log stock returns over the prior three months (SIGMA), estimated by:

$$
S I G M A_{i, m-1, m-3}=\left(252 * \frac{1}{N-1} \sum_{k \epsilon\{m-1, m-2, m-3\}} r_{i, k}^{2}\right)^{\frac{1}{2}}
$$

where $r_{i, k}$ is the $\log$ stock return of firm $i$ on day $k$, and $N$ is the number of trading days in the 3-month estimation interval SIGMA is set to missing if there are fewer than five non-zero daily returns. However, to avoid excluding illiquid stocks from our sample, we replace missing values for SIGMA with the corresponding country-month cross-sectional mean. We further use relative market size (RSIZE), defined as the log ratio of the firm's market value to the total market value of firms in the same country-month. Finally, following Campbell et al. (2008), we also use log share price (PRICE) as a default risk indicator to capture the inability of distressed firms to engage in reverse stock splits, implying that such firms often trade at low share prices.

In the remainder, we collectively refer to NIMTA, TLMTA, EXRET, RSIZE, SIGMA, CASHMTA, MB, and PRICE as the CHS default risk indicators. Whereas NIMTA, TLMTA, RSIZE, and MB are currency-free, EXRET, SIGMA, and PRICE are measured in local cur-

\footnotetext{
${ }^{8}$ We have also experimented with versions of NIMTA and TLMTA scaled by the book value of total assets rather than its market-value adjusted counterpart. Similar to Campbell et al. (2008), we have found that using the book value of total assets decreases the ability of NIMTA and TLMTA to forecast bankruptcy.

${ }^{9}$ To make sure that book values of equity that are close to zero do not yield extreme values when used in the denominator of MB, we follow Cohen et al. (2003) in adding 10\% of the difference between the market and the book value of equity to the latter. In the few cases where this adjustment does not generate a positive book value of equity, we follow Campbell et al. (2008) and set it equal to one unit of the local currency.
} 
rency. To alleviate the effect of outliers, we winsorize the default risk indicators at the $5^{\text {th }}$ and $95^{\text {th }}$ percentiles, computed for each country-month distribution separately. The only exception is PRICE, which is winsorized at the $25^{\text {th }}$ and $75^{\text {th }}$ percentiles.

Market data are sourced from Thomson Datastream at daily and monthly frequencies. We consider only shares traded in local currency and exclude non-primary issues. Accounting data are sourced from Worldscope at an annual frequency because quarterly data are unavailable for most non-US firms before 2000. Where necessary, we convert the accounting items into the currency of the issue using the Thomson Datastream conversion factors. As the reporting gap can be substantially longer in international markets than in the US (DeFond et al., 2007), we assume that the accounting items are available to investors six months after the fiscal year end. To avoid dropping firms shortly before their filing date, we further assume that investors use outdated data for up to twelve months if more recent data are unavailable.

Table 2 reports descriptive statistics for the default risk indicators of active and bankrupt firms. The default risk indicators of the bankrupt firms are measured in the month prior to their filing $(t-1)$. The table suggests that firms filing for bankruptcy are in general less profitable (NIMTA), more levered (TLMTA), and more volatile (SIGMA) than non-bankrupt firms. They also tend to have lower stock returns (EXRET), market-to-book ratios (MB), and log stock prices (PRICE) relative to non-filing firms. However, deviating from Campbell et al. (2008), filing firms do not hold considerably less cash (CASHMTA) on average.

[Table 2 here]

A more detailed inspection of Table 2 reveals notable differences between filing and nonfiling firms across countries. For example, firms filing for bankruptcy in Japan are only slightly less profitable relative to non-bankrupt firms. In particular, the difference in their average NIMTA is only -0.03 , whereas it is much larger in the other countries, with the exception of France where the difference is also relatively small (-0.08). Moreover, German firms do not use up their internal slack to delay bankruptcy filings, and hence they typically enter bank- 
ruptcy with more cash holdings (mean=0.16) than filing firms in the other countries of our sample.

An explanation for these features could be that both France and Germany have "stopearly" bankruptcy regimes. In France, managers are obliged to file for bankruptcy within 45 days, once the value of their liquid assets drops below that of their short-term liabilities. In fact, it is the French court that ultimately decides whether a bankrupt firm should be restructured, and its main objectives are to keep the firm alive, to preserve employment, and to satisfy creditors (Kaiser, 1996). In Germany, managers are also obliged to file within three weeks if firm net worth drops below a specific threshold. Failure to do so can render managers personally liable to creditors (Wood, 2007).

Whereas there are no similar obligations in Japan, it is possible that Japanese banks are able to use their dominant position to force managers to file early, while the bank's claims are still relatively secure (Pinkowitz and Williamson, 2001). This feature may also explain why the stock returns of Japanese firms prior to filing are, on average, the least negative relative to filing firms in the other countries.

Overall, the univariate analysis in Table 2 highlights important cross-country variations in the ability of the default risk indicators to distinguish between bankrupt and non-bankrupt firms. These variations can often be linked to differences in bankruptcy codes or institutional features across countries. This evidence motivates the estimation of country-specific LOGIT models to compute default probabilities, as described in Section 3.

\subsection{Market, Size, Value, and Momentum Factors}

Our asset pricing tests adjust portfolio returns for their market, size, value, and momentum factor exposures, using the CAPM, the Fama-French (FF) 3-factor model, and the FamaFrench-Carhart (FFC) 4-factor model, respectively. To this end, we use the Developed Markets Global ex US Fama-French market, size, value, and momentum factors, which are avail- 
able from Kenneth French's online data library; ${ }^{10}$ see Fama and French (2012, p. 459-460), for their construction details. Interestingly, the set of developed markets that are used to construct the above factors has a very large degree of overlap with the C14 countries that we use in our study, rendering these factors appropriate for risk-adjusting our portfolio returns. ${ }^{11}$

We have additionally used two alternative sets of factors to risk-adjust portfolio returns. First, we have computed our own market, size, value, and momentum factor returns using the same universe of stocks as the one used to construct portfolios for the C6 and C14 countries, respectively. Second, we have computed market, size, and value factor returns using the returns on the relevant MSCI World ex US Indices. The Supplementary Appendix discusses the construction of these factors and reports the corresponding asset pricing results. In sum, the magnitude and significance of the international default risk premium that we report in the benchmark results remain robust to the use of the alternative sets of factors.

\section{Forecasting Bankruptcies Around the World}

\subsection{The Bankruptcy Forecasting Model}

Following Campbell et al. (2008, 2011), we use a reduced-form hazard model to construct our default risk measure (see also Shumway, 2001; Chava and Jarrow, 2004; Hillegeist et al., 2004; O'Doherty, 2012). This hazard model specifies the probability of bankruptcy 12 months ahead conditional on survival in the interim 11 months as:

$$
\operatorname{Prob}_{m-12}\left(Y_{i, m}=1 \mid Y_{i, m-1}=0\right)=\frac{1}{1+\exp \left(-\alpha-\boldsymbol{\beta}^{\prime} \boldsymbol{X}_{i, m-12}\right)},
$$

where $Y_{i, m}$ is a dummy variable that equals one if firm $i$ files for bankruptcy in month $m$ and zero otherwise, and $\boldsymbol{X}_{\boldsymbol{i}, \boldsymbol{m}-\mathbf{1 2}}$ is a vector containing the publicly available values (i.e., allowing for a reporting gap for the accounting items) of the default risk indicators for firm $i$ in month

\footnotetext{
${ }^{10} \mathrm{http}: / / \mathrm{mba}$.tuck.dartmouth.edu/pages/faculty/ken.french/data_library.html\#Developed.

${ }^{11}$ For the list of countries used to construct the Developed Markets Global ex US Fama-French factors, see: http://mba.tuck.dartmouth.edu/pages/faculty/ken.french/Data_Library/details_globalexus.html.
} 
$m-12$. We term the default probability estimated from the above hazard model as the CHS default risk measure. The standard LOGIT specification in (2) implies that this default risk measure is a non-linear transformation of the firm characteristics that are used to compute it.

We firstly estimate the LOGIT model in (2) for each of the C6 countries. For the remaining eight countries that feature too few (less than 40) bankruptcies to be analyzed separately, we pool the data by bankruptcy law regime and estimate the corresponding regime-specific LOGIT model. Following Wood (2007), we assign Australia, Canada, Hong Kong, New Zealand, and the UK to the common law regime; France, Spain, and Portugal to the Napoleonic regime; Denmark, Finland, Germany, and Sweden to the Roman-Germanic regime; and Taiwan and Japan to the mixed regime.

The estimation of country- and bankruptcy regime-specific LOGIT models provides an important source of flexibility relative to estimating a single (global) LOGIT model. In particular, this approach allows us to capture cross-country variations with respect to average default rates (through the constant term) as well as the contribution of the various default risk indicators (through the coefficients in $\boldsymbol{\beta}$ ). This is an important feature since we subsequently use these estimated default probabilities to sort the entire cross-section of stocks into international portfolios.

Whereas in-sample default probability estimates are informative, they are obviously not available to investors in real time, and hence they would induce a look-ahead bias in our asset pricing tests. Therefore, our asset pricing tests make use of out-of-sample (OOS) default probabilities that are based on recursive estimations of model (2). Determining the initial estimation window, we face the following dilemma. On the one hand, OOS default probabilities should be estimated using sufficiently long windows to ensure that the default risk proxy is precisely estimated. On the other hand, asset pricing tests should be conducted over sufficiently long time periods to derive meaningful results. We opt for an initial estimation window using data up to December 1999. This choice ensures that each window includes at least 
five bankruptcy filings for each country, and allows us to perform asset pricing tests using 15 years of monthly returns.

Having estimated each LOGIT model using data until December of year $t-1$, we combine the recursively estimated coefficients with the corresponding publicly available values for the default risk indicators in December of year $t-1$ to compute OOS default probabilities for each firm and each month in the following year $t$, as in Campbell et al. (2008).

We compare CHS with a popular default risk proxy, Merton's (1974) Distance-to-Default (MDD). This is given by:

$$
M D D_{i, t}=\frac{\ln \left(\frac{V_{i, t}}{X_{i, t}}\right)+\left(\mu_{i, t}-.5 \sigma_{i, t}^{2}\right)}{\sigma_{i, t}}
$$

where $V_{i, t}$ is the implied asset value, $\sigma_{i, t}$ is the estimated asset volatility, $\mu_{i, t}$ is the mean return of the implied asset value series, and $X_{i, t}$ is the default-triggering asset value. To compute MDD, we require the market value of equity, the default-triggering asset value, and the riskfree rate. Following Crosbie and Bohn (2003) and Vassalou and Xing (2004), we set the default-triggering asset value equal to the book value of short-term debt plus one-half of the book value of long-term debt. We use the local 3-month interest rate as a proxy for the riskfree rate of return.

We follow Vassalou and Xing (2004) in computing MDD. In particular, we use as initial guess of the firm's asset volatility its stock return volatility, calculated from daily data over the prior twelve months. Using this initial guess together with the market value of equity, the default-triggering asset value, and the risk-free rate, we derive the firm's asset value from the Black and Scholes (1973) call option formula on each trading day over the prior twelve months. The time-series of asset values allow us to derive a new estimate of the firm's asset volatility. We iterate this process until the asset volatility estimate converges. Plugging the asset volatility estimate and the other variables into (3), we obtain MDD. By construction, MDD is available OOS. As with CHS, MDD also captures default risk twelve months ahead. 
Computing MDD from (3), the corresponding implied default probability is given by:

$$
\pi_{M D D, i, t}=\mathcal{N}\left(-M D D_{i, t}\right)
$$

where $\mathcal{N}(\cdot)$ is the normal cumulative density function. Throughout the remainder, we term the MDD-implied default probability as the MDD default risk proxy. ${ }^{12}$

\subsection{Estimates of the In-Sample LOGIT Models}

Table 3 reports the full sample estimates of the LOGIT model in (2) for each of the C6 countries. For the sake of brevity, we do not report the results for the bankruptcy law regimes, but these are available upon request. In general, the reported results confirm the univariate analysis from the descriptive statistics in Table 2. In particular, the default probability tends to increase with total liabilities (TLMTA) and stock return volatility (SIGMA), whereas it tends to decrease with profitability (NIMTA), excess returns (EXRET), relative size (RSIZE), and cash holdings (CASHMTA). Based on their significance levels, TLMTA, RSIZE, and SIGMA are the most important default risk indicators. The log stock price (PRICE) is related to the default probability with an ambiguous sign, whereas MB is insignificant in most cases.

[Table 3 here]

Using the same LOGIT model to forecast US failures, Campbell et al. (2008) report a pseudo- $\mathrm{R}^{2}$ of $11.4 \%$ for a 12 -month forecasting horizon. Noting that we do not consider performance-related delistings, and that our sample period is shorter, the pseudo- $\mathrm{R}^{2} \mathrm{~s}$ in Table 3 suggest that this LOGIT model also exhibits good forecasting power for the countries we examine, which is particularly high in France (9.4\%), Canada (9.2\%) and Japan (8.3\%).

The results reported in Table 3 also suggest that there are notable variations in the estimated coefficients of the default risk indicators across countries. These variations are often,

\footnotetext{
${ }^{12}$ In the Supplementary Appendix, we alternatively compute MDD using two other proxies for the expected return of firms' assets, and we re-examine the performance of the MDD-sorted portfolios. Using either of these two alternative proxies, the corresponding MDD-based asset pricing results are very similar to the ones derived using the benchmark approach that is presented here.
} 
albeit not always, consistent with the patterns revealed by the descriptive statistics in Table 2 . For example, CASHMTA is insignificant in Germany and NIMTA is insignificant in Japan. To test whether cross-country variations in the estimated coefficient of a default risk indicator are statistically significant, we pool all countries' data and estimate a single LOGIT model with a complete set of country interaction terms (unrestricted model). We then take turns in dropping the country interaction terms associated with each default risk indicator (restricted model), re-estimate the model, and compute the corresponding likelihood ratio (LR) test. The last column in Table 3 reports these LR statistics, suggesting the rejection of the null hypothesis of no cross-country variations for all default risk indicators, except for EXRET.

\subsection{Bankruptcy Forecasting Ability Comparison between CHS and MDD}

Advocating the use of CHS as a default risk proxy for our international sample, we compare its bankruptcy forecasting ability with the one of MDD. To this end, we perform both insample and out-of-sample tests, similar to the ones performed by Campbell et al. (2008) and Bharath and Shumway (2008) for the US market.

With respect to in-sample tests, Table 4 presents the results from country-specific LOGIT models that include either only MDD (Panel A), or MDD together with the CHS default risk indicators (Panel B), or only the CHS default risk indicators (Panel C). These models are estimated using only firm-month observations for which both MDD and the CHS default risk indicators are available. Panel A suggests that, on its own, MDD is a significant predictor of bankruptcy, and its coefficient carries the correct sign. However, the results reported in Panel B show that adding the CHS default risk indicators to the model substantially decreases the magnitude of the MDD coefficient, which now becomes insignificant in 3 out of 6 countries. Equally importantly, comparing pseudo- $\mathrm{R}^{2}$ s between Panels $\mathrm{A}$ and $\mathrm{B}$, we find that adding the CHS default risk indicators to MDD doubles the bankruptcy forecasting power of the LOGIT 
models across all countries, with the exception of Germany where the increase is still notable but not that high.

\section{[Table 4 here]}

Another way to confirm the in-sample superiority of the CHS default risk indicators is to compare how the LOGIT models' pseudo- $\mathrm{R}^{2}$ s change when we add MDD on top of these indicators. Comparing the pseudo- $\mathrm{R}^{2} \mathrm{~s}$ in Panel $\mathrm{C}$ with the ones in Panel $\mathrm{B}$, it becomes apparent that MDD has a negligible contribution to the models' explanatory power, again with the exception of Germany. In sum, the CHS default risk indicators subsume the bankruptcy-relevant information contained in MDD. These results closely resemble the ones reported in Campbell et al. (2008) for the US market, confirming the in-sample superiority of these default risk indicators relative to MDD in our international setup. Moreover, these results echo the conclusion of Bharath and Shumway (2008) that MDD is not a sufficient statistic for default risk.

To assess the out-of-sample bankruptcy forecasting ability of these two default risk measures, we compute their corresponding accuracy ratios following the approach of Vassalou and Xing (2004, p. 842-843). In particular, for each of these two measures we rank firms in descending order according to their default probabilities estimated in December of year $t-1$ and then compute the corresponding areas under curve using the actual defaults that occurred in year $t$. The area under curve reflects the portion of firms that actually defaulted within a given percentage of firms with the highest default risk. The accuracy ratio is given by the ratio of each measure's area under curve divided by the area under curve of the "perfect foresight measure", which could ex ante assign the highest rank exactly to those firms that subsequently defaulted. The accuracy ratio of the perfect default risk measure would be equal to 1 , whereas the accuracy ratio of a zero-information measure would be equal to 0 .

We compute the accuracy ratios for each of the two default risk measures in each year of our sample. For the C6 (C14) countries, CHS yields an average accuracy ratio of 0.667 (0.668), whereas the corresponding figure for MDD is 0.595 (0.591). Interestingly, CHS also 
yields a higher average accuracy ratio for each of the C6 countries (see Panel D of Table 4). These results confirm the ability of CHS to predict out-of-sample corporate defaults in our international sample, both in absolute and in relative terms.

To further assess the out-of-sample bankruptcy forecasting ability of these two default risk measures, we have also performed a portfolio-based analysis, which is presented in the Supplementary Appendix. In sum, we find that CHS exhibits a superior ability to ex ante classify as extremely high default risk a notably higher portion of firms that subsequently filed for bankruptcy.

\section{The International Default Risk Premium}

\subsection{Default Risk and Stock Returns in the C6 and C14 Countries}

In this section, we examine the performance of international default risk-sorted portfolios. In our benchmark tests, we use monthly portfolio returns that are calculated from the perspective of an international investor and are expressed in US dollar (USD) terms. Similarly, excess portfolio returns are computed in excess of the USD risk-free rate. In particular, we sort the entire cross-section of stocks in ascending order on the basis of their CHS estimates in December of each year $t-1$ and assign them to international quantile portfolios. For our benchmark analysis, we follow the practice of Da and Gao (2010) and calculate portfolio returns from February of year $t$ to January of year $t+1$; that is, we allow for a one-month gap between portfolio formation and the beginning of the 12-month holding period to alleviate concerns that portfolio performance is driven by a short-term return reversal effect.

Since non-US stock return data can be of lower quality, we impose several data filters. In particular, our main results exclude a stock in year $t$ if its market capitalization or its price in December of year $t-1$ is lower than the $5^{\text {th }}$ percentile of the corresponding country-month distribution. Using these filters, we alleviate concerns that the performance of high default risk portfolios is driven by microcap stocks or microstructure biases. We calculate both value- 
weighted (vw) and equally-weighted (ew) portfolio returns. We report average excess portfolio returns as well as portfolio alphas adjusted for market risk (CAPM alphas) or, alternatively, for market, size (SMB), value (HML), and momentum (MOM) factor exposures according to the FFC model (FFC alphas). Reported returns and alphas are annualized.

In Table 5, we report the premia of several quantile portfolios constructed on the basis of OOS CHS estimates for the C6 (Panel A) and C14 countries (Panel B) during the period 2000-2014. To measure the default risk premium, we calculate the return of a spread strategy that is long the quintile portfolio with the highest default risk stocks (Q5) and short the quintile portfolio with the lowest default risk stocks (Q1). Finally, we also calculate the corresponding return of a spread strategy that is long the decile portfolio with the highest default risk stocks (P10) and short the decile portfolio with the lowest default risk stocks (P1).

[Table 5 here]

The results in Table 5 show that average premia and CAPM alphas increase almost monotonically as we move from low to high default risk portfolios across both the C6 and the C14 countries. In the case of value-weighted portfolios, the average return of the spread strategy Q5-Q1 is equal to $13.86 \%$ p.a. in the C6 and $13.42 \%$ p.a. in the C14 countries, indicating the existence of an economically significant default risk premium. The premium is also highly statistically significant (C6 countries t-stat: $2.71, \mathrm{C} 14$ countries t-stat: 3.03$).{ }^{13}$ Moreover, the premium is of similar magnitude when we use equally-weighted portfolio returns: $10.24 \%$ p.a. (t-stat: 2.43 ) in the $\mathrm{C} 6$ and $9.99 \%$ p.a. (t-stat: 2.66$)$ in the $\mathrm{C} 14$ countries.

Adjusting for market risk, the magnitude and the significance of the premium are not affected. This result originates from the fact that the average excess market return over the examined sample period has been quite low (3.83\% p.a.), so potentially different market exposures cannot explain the default risk premium. In particular, in the C14 countries, the spread

\footnotetext{
${ }^{13}$ Newey-West (1987) standard errors are used for the calculation of the reported t-statistics.
} 
strategy Q5-Q1 yields a CAPM alpha of $12.26 \%$ p.a. (t-stat: 2.83 ) in the case of valueweighted portfolios and $8.86 \%$ p.a. (t-stat: 2.88 ) in the case of equally-weighted portfolios.

It should be noted that in the case of equally-weighted returns, the default risk premium is predominantly driven by the significantly high excess returns and alphas that the high default risk stocks yield. In the case of value-weighted returns, the portfolios containing the lowest default risk stocks exhibit negative (but insignificant) excess returns and significantly negative CAPM alphas. Therefore, in this case, the documented premium appears to be driven both by the outperformance of the highest default risk stocks and the underperformance of the lowest default risk stocks. As discussed in the Supplementary Appendix, a potential explanation for this underperformance is that the lowest default risk quintile portfolio can provide a hedge against increases in aggregate default risk. ${ }^{14}$

Furthermore, when we adjust portfolio returns for their size, value, and momentum factor loadings, the default risk premium is reduced by a third in the case of value-weighted portfolios. In particular, the FFC alpha of the spread strategy Q5-Q1 is 8.13\% p.a. (t-stat: 2.16) in the C6 and $7.86 \%$ p.a. (t-stat: 2.80 ) in the $\mathrm{C} 14$ countries. Figure 1 illustrates why adjusting for these additional factors reduces the alphas of the spread strategies in the case of valueweighted portfolio returns. In particular, the portfolios containing the highest default risk stocks exhibit much higher SMB and HML betas relative to the portfolios containing the lowest default risk stocks, with the lowest default risk portfolios exhibiting negative HML betas. Since the SMB and HML factors carry positive premia in our sample period, adjusting for value and size factor exposures reduces the magnitude of the default risk premium relative to the CAPM. At the same time, however, the highest default risk stocks are typically past year losers, so their portfolios exhibit negative MOM betas (see Figure 1). Therefore, the resulting

\footnotetext{
${ }^{14}$ In particular, following the approach of Kapadia (2011), we find that the returns of the lowest (highest) default risk quintile portfolio are positively (negatively) associated with contemporaneous changes in aggregate default risk, as measured by the median CHS default probability across firms in a given month. As a result, in line with intertemporal asset pricing theory, a risk averse investor may be willing to hold low default risk stocks, despite their underperformance, so as to hedge against adverse shocks in aggregate default risk.
} 
default risk premium is higher when we adjust returns using the FFC model as compared to the FF model (results from the FF model are available upon request). Finally, we should note that in the case of equally-weighted portfolios, the magnitude and the statistical significance of the default risk premium remain intact regardless of the model we use to perform the riskadjustment. $^{15}$

[Figure 1 here]

Whereas our results are certainly not driven by under-diversification (see the high number of stocks per portfolio), a potential concern is that they may be attributable to estimation error in the initial estimation windows, since these are often based on few bankruptcy filings. Figure 2 addresses this concern by plotting the cumulative profits of a trading strategy that is long the decile portfolio with the highest OOS CHS stocks (P10) and short the decile portfolio with the lowest OOS CHS stocks (P1). This figure shows that the profits of this strategy are not attributable solely to the initial years of the test period, and hence the reported magnitude of the default risk premium cannot be driven by estimation error in the initial windows. Another interesting conclusion derived from Figure 2 is that high default risk stocks outperformed during the 2003-2006 and 2009-2010 bull market periods, whereas, as expected, they were severely hit during the 2007-2008 global financial crisis. These patterns confirm that, in line with standard asset pricing theory, the highest default risk stocks perform poorly during "bad times", rendering them very risky, but earn a high premium during "good times" to compensate risk averse investors for holding them.

[Figure 2 here]

\footnotetext{
${ }^{15}$ Equally-weighted portfolio returns and CAPM alphas are higher than the corresponding value-weighted portfolio returns and alphas across all default risk quantiles. This pattern is consistent with the existence of a significant size effect in our sample of international developed markets. The significance of this size effect is also confirmed in Fama-MacBeth regressions (see Table 7). Once we adjust portfolio returns for their SMB factor loadings via the FFC model, the wedge between equally- and value-weighted FFC alphas reported in Table 5 is reduced for the low and medium default risk portfolios, whereas it remains large for the highest default risk portfolio. This finding is consistent with the conjecture that there is a particular size effect within the highest default risk stocks, beyond the systematic size effect that is captured by the SMB factor. This finding may also be related to the very high idiosyncratic volatility that the highest default risk stocks exhibit.
} 


\subsection{Robustness Checks}

Table 6 reports the results from a series of robustness checks with respect to the magnitude of the default risk premium in the C6 (Panel A) and the C14 countries (Panel B). To save space, we only report the average excess returns of the extreme CHS-sorted quintile portfolios Q1 and Q5 as well as of the spread strategy Q5-Q1. Results for all other portfolios and riskadjusted returns are available upon request.

\section{[Table 6 here]}

In the first robustness test, we set the returns of filing firms to $-100 \%$ during their filing month, examining whether missing delisting returns could have led to an overestimation of the default risk premium reported in our benchmark results. In the second robustness test, we impose additional data filters. ${ }^{16}$ In the third robustness test, we do not impose a one-month gap between the portfolio formation date (December of year $t-1$ ) and the beginning of the holding period, which now becomes January of year $t .{ }^{17}$

The corresponding results reported in Table 6 show that the premium derived from the spread strategy Q5-Q1 remains economically and statistically significant, and is very similar to the benchmark results reported in Table 5. The unreported CAPM and FFC portfolio alphas are also similar to the corresponding alphas reported in Table 5. More specifically, adjusting for market risk does not affect the magnitude of the default risk premium. However, adjusting for size and value premia captures part of the default risk premium, because the returns of the high default risk portfolios are positively associated with the SMB and HML factor returns. Nevertheless, the default risk premium remains significant in most cases.

In addition, we have alternatively computed the international default risk premium as a value-weighted average of country-level premia. In particular, we firstly sort stocks into quan-

\footnotetext{
${ }^{16}$ In particular, we additionally omit stocks with a zero ex-dividend monthly return and stocks with incomplete market and accounting data in the year up to portfolio formation.

${ }^{17}$ We have also repeated this analysis using alternatively a longer gap of two or three months. Interestingly, we find that a longer gap renders the default risk premium larger and more significant.
} 
tile portfolios for each country, and then average across countries. In this way, we can examine whether the reported default risk premium in our benchmark results is driven by withincountry or across-country variation in default probabilities. Unreported results, which are available upon request, show that the international default risk premium remains significant, especially when country-level portfolios are formed using equal weights. However, it is reduced relative to our benchmark approach. These results show that both within-country and across-country variation in default probabilities plays a role in the formation of the international default risk premium, but the latter yields a stronger effect. ${ }^{18}$

Finally, we have also examined whether FOREX effects could influence the magnitude of the reported default risk premium. In particular, in the unlikely case that the highest (lowest) default risk stocks in a given month are predominantly domiciled in countries whose currencies simultaneously appreciate (depreciate) relative to the USD, then the reported default risk premium could have been driven by exchange rate movements rather than a genuine outperformance of the highest default risk stocks. To address this potential concern, we have examined the country composition of the default risk portfolios. We confirm that none of these portfolios is dominated by firms domiciled in a single country. This is particularly true for the highest and the lowest default risk portfolios that give rise to the reported premium. ${ }^{19}$

\subsection{Fama-MacBeth Regressions}

In this section, we further examine how robust is the positive relation between the CHS default risk measure and subsequent stock returns using Fama-MacBeth regressions. In particular, for each month of our sample we run cross-sectional regressions of excess stock returns on lagged CHS estimates and a series of lagged firm characteristics. Table 7 reports the aver-

\footnotetext{
${ }^{18}$ We would like to thank an anonymous referee for suggesting this robustness test.

${ }^{19}$ Moreover, in unreported results, we have alternatively computed portfolio returns using local currency stock returns, i.e., without converting them to USD returns. In this case, we find that the default risk premium remains positive and significant, and hence we exclude the possibility that exchange rate movements may be driving the reported default risk premium.
} 
age slope coefficients estimated from these monthly regressions as well as their t-statistics computed using Newey-West standard errors. We have normalized each regressor by its standard deviation, and hence the corresponding Fama-MacBeth estimate can be interpreted as the effect of a one standard deviation increase in this firm characteristic on stock premia.

[Table 7 here]

Model 1 in Table 7 includes only CHS as regressor, documenting a strongly significant positive relation between default risk and stock premia (t-stat: 7.23). The magnitude of the CHS coefficient accurately reflects the magnitude of the default risk premium derived from the univariate portfolio sorts in Table 5. In particular, a one standard deviation increase in default probability would increase the stock premium by 86 basis points per month. Model 2 controls for firms' beta, size and book-to-market value ratio. The results show that CHS is significantly priced in the presence of these commonly used firm characteristics, and hence it does not simply capture a size effect, even though the magnitude of the CHS coefficient is almost halved, as expected.

Another potential concern is that the positive relation between default risk and stock premia may be driven by a short-term return reversal effect (see Lehman, 1990, and Da and Gao, 2010) or by microstructure biases, such as the bid-ask bounce or infrequent trading, which are more pronounced for firms traded at low prices (see Blume and Stambaugh, 1983; Lo and MacKinlay, 2001). To address this concern, Model 3 additionally controls for momentum, reversal and price effects. Whereas we find that the reversal and price effects are significant indeed, the magnitude and the significance of the examined relation remain intact in the presence of these additional control variables. Finally, Model 4 also includes the default risk indicators that are used to estimate the CHS measure but are not already accounted for in the previous model specifications. In particular, we additionally control for stock return volatility (SIGMA), profitability (NIMTA), leverage (TLMTA) and cash holdings (CASHMTA). In this way, we address the potential concern that CHS may simply capture the explanatory 
power of these firm characteristics with respect to stock premia. We find that the magnitude and significance of the CHS coefficient remain remarkably robust to the inclusion of these variables; CHS is priced in the cross-section of our international sample of stocks over and above its constituent variables. This is because CHS is a country-specific, non-linear transformation of these firm characteristics, and hence their inclusion in the regression model in a linear fashion cannot absorb the explanatory ability of CHS.

Fama-MacBeth regressions also allow us to address the potential concern that the positive relation between default risk and stock returns may be driven by a particular country effect. To this end, we include a set of country dummies and re-estimate the previous model specifications. In particular, Model 5 includes only CHS apart from the country dummies, whereas Model 6 also contains the full set of firm characteristics that we used in Model 4. The results reported in Table 7 convincingly show that the benchmark results reported for Models 1 and 4 remain unaffected by the addition of the country dummies. Based on this evidence, we conclude that the positive cross-sectional relation between default risk and stock returns is genuine and it is not driven by a particular country effect.

\subsection{MDD-sorted Portfolios}

The previous results indicate a robust positive default risk-stock return relation, which is markedly different from the findings of EGZ and GPS, who use MDD and EDF, respectively, to proxy for default risk. In this section, we examine the source of these different findings. To this end, we repeat the portfolio formation exercise using MDD as an alternative portfolio sorting criterion. MDD should be a close proxy for the proprietary EDF proxy, which is neither publicly available nor replicable for our international sample. For comparison purposes, we also report the corresponding results using our CHS estimates. However, the CHS portfolios are now constructed using only firms for which both CHS and MDD are available, to en- 
sure that the same sample is examined. Table 8 reports equally- and value-weighted excess portfolio returns during the period 2000-2014 for both default risk measures.

[Table 8 here]

The results confirm the almost monotonic relation between CHS and portfolio premia for this subsample of firms. In sharp contrast, when MDD is used as sorting variable, a U-shape relation between default risk and portfolio returns emerges. As a result, the corresponding spread strategies using either quintile or decile portfolios yield premia that are very close to zero and insignificant. This finding is consistent for both value-weighted and equallyweighted portfolio returns in the $\mathrm{C} 6$ and $\mathrm{C} 14$ countries. Hence, we confirm that using MDD as a default risk proxy, one would conclude that there is no default risk premium in our international sample, corroborating the puzzling evidence for the US market.

Even though we confirm the findings of GPS and EGZ regarding the lack of a default risk premium on the basis of MDD, we have shown that MDD is an inferior default risk proxy relative to CHS, both in-sample and out-of-sample (see Section 3.3). In fact, the difference in the default risk premium estimates obtained from the two sets of portfolios is caused by the fact that CHS and MDD disagree on identifying both the lowest and the highest default risk firms. This discrepancy is exacerbated among the lowest default risk stocks and it becomes evident by examining the average CHS values across the MDD-sorted portfolios in the C14 countries. Though the firms in the highest MDD portfolios also exhibit the highest average CHS values, the lowest MDD decile portfolio (P1) contains firms with higher than average CHS estimates. Consistent with our previous findings, this portfolio yields a relatively higher mean excess return, exactly because it contains moderately distressed firms according to the CHS measure.

A reason why these two proxies disagree on the classification of low default risk stocks is that Merton's model assumes that default occurs once the asset value drops below a fraction of the book value of debt, implying that a zero default risk is assigned to stocks with no debt. Consistent with this idea, unreported results show that once we drop zero leverage firms from 
our sample, the U-shape relation between MDD and portfolio returns becomes less pronounced. Moreover, Merton's model fails to take into account bankruptcy-triggering reasons other than insolvency. For example, Davydenko (2008) finds that, although most bankrupt firms are insolvent and illiquid, a fraction of them are only illiquid. Given that structural models, including the one used by Moody's KMV, usually abstract from liquidity reserves, these models possibly classify firms with liquidity problems as low default risk. ${ }^{20}$

\section{What Drives the International Default Risk Premium?}

This section examines what drives the significant international default risk premium documented on the basis of the CHS measure in Section 4. In particular, we examine whether a series of country-level characteristics affect the magnitude and the significance of this premium.

Motivated by the evidence of Favara et al. (2012), we ask whether cross-country variations with respect to creditor protection rights and shareholders' ability to renege outstanding debt affect the default risk premium. As Djankov et al. (2008) highlight, insolvency procedures considerably vary across countries; in countries where the legal framework and judicial practices favor debt renegotiation and increase shareholders' bargaining power relative to creditors', we expect default risk to be less significantly priced. This is because shareholders' expected payoffs in default may be higher, motivating them to default for strategic rather than solvency reasons. On the other hand, in countries where creditors have strict priority and can recover the proceeds of the insolvency procedure quickly and without incurring considerable costs, shareholders' ability to extract rents from creditors is low, and hence the former should require a significant premium to invest in high default risk firms.

\footnotetext{
${ }^{20}$ In the Supplementary Appendix, we also consider hybrid MDD default risk measures and examine their asset pricing implications. In sum, we find that adding only one of the CHS indicators to MDD is not sufficient to yield a positive relation between the corresponding hybrid default risk measure and future stock returns. However, the hybrid MDD measure computed by using the full set of CHS indicators together with MDD yields a significant positive default risk premium.
} 
To test these conjectures, we construct double-sorted portfolios on the basis of CHS and two alternative proxies for creditor rights at the country level. In particular, we use the Renegotiation Failure Index and the Creditors' Recovery Rate from the survey of Djankov et al. (2008). ${ }^{21}$ The Renegotiation Failure Index summarizes a number of characteristics of debt enforcement procedures that protect creditors from shareholders' strategic default (see Djankov et al., 2008, and Favara et al., 2012, for details). The higher the index score, the more difficult it is for shareholders to attempt to renege the outstanding debt. Creditors' $R e$ covery Rate is an inverse measure of the shareholders' benefits to engage in strategic default. This index takes into account not only the order in which secured creditors are paid, but also the overall estimated costs of the insolvency procedure as well as its duration. The higher the creditors' recovery rate, the lower the shareholders' bargaining power.

The results from these double-sorted portfolios are reported in Table 9. We find that the default risk premium is economically and statistically significant mainly in countries where shareholders face considerable frictions in attempting to renegotiate the outstanding debt (High Renegotiation Failure) as well as in countries where creditors' recovery rate is high. This evidence is in line with the arguments of Favara et al. (2012), showing that when shareholders' bargaining power and their ability to extract rents from creditors are low, then the former require a significant default risk premium, which is close to $10 \%$ p.a.. To the contrary, in those countries where shareholders' bargaining power is high and the judicial process favors debt renegotiation, the default risk premium is lower and statistically insignificant, since shareholders' expected payoffs in default are higher, and hence default risk carries a lower price. These results hold for both value-weighted and equally-weighted portfolios. ${ }^{22}$

[Table 9 here]

\footnotetext{
${ }^{21}$ Available on Andrei Shleifer's website: http://scholar.harvard.edu/shleifer/.

${ }^{22}$ The explanation we put forward for the difference in the reported default risk premia implies that the price of default risk is high and significant only in the countries with high creditor protection and low shareholder bargaining power. However, this argumentation does not exclude the possibility that the spread between firms' default probabilities could also be larger in these countries, thus contributing to the reported default risk premium differential.
} 
To further examine the shareholder advantage hypothesis at the firm level, we also construct double-sorted portfolios on the basis of CHS and firm tangibility. As Garlappi et al. (2008) and Garlappi and Yan (2011) argue, shareholders' bargaining power decreases with asset tangibility, proxied by the ratio of property, plant and equipment to total assets. This is because the more tangible the assets are, the easier and less costly it is for creditors to liquidate them in the case of bankruptcy. The corresponding results from these double-sorted portfolios, which are reported in Table 9, strongly support the shareholder advantage hypothesis. In particular, the default risk premium among firms with highly tangible assets is twice as high as the corresponding premium among firms with low tangibility. Actually, in the case of equally-weighted portfolios, the premium becomes insignificant among firms with low tangibility.

Though our results strongly support the shareholder bargaining power hypothesis of Garlappi et al. (2008) at the firm level and Favara et al. (2012) at the country level, in the Supplementary Appendix we also examine alternative country-level characteristics as potential drivers of the international default risk premium. First, following GPS, we examine whether country-level investor overconfidence, as proxied by Hofstede's (2001) individualism index, has an effect on the price of default risk. Moreover, we examine whether the documented premium is affected by the depth of the local stock market, as proxied by its total trading volume relative to the country's GDP, or by the degree of information asymmetry between firm managers and investors, as captured by the Accounting Standards Index of La Porta et al. (1998). The corresponding results show that none of these alternative country-level characteristics has a considerable effect on the default risk premium, since this remains significantly positive among countries with both high and low values of these characteristics. 


\section{Systematic vs. Idiosyncratic Default Risk}

Our benchmark asset pricing results utilize CHS values estimated from LOGIT models to classify firms as high versus low default risk. However, a growing strand of the literature (see Anginer and Yildizhan, 2014; Friewald et al., 2014; and Hilscher and Wilson, 2015) argues that, in equilibrium, investors should require a premium for being exposed to systematic rather than firm-specific default risk. This is because systematic default risk is nondiversifiable; default events are typically correlated and their cost depends on their timing. In fact, Hilscher and Wilson (2015) introduce the concept of "failure beta", defined as the sensitivity of a firm's default probability to the median cross-sectional default probability, and they show that it is a meaningful proxy for systematic default risk. Motivated by these arguments, in this section we decompose firms' total default risk into its systematic and idiosyncratic components and examine which of the two is priced in our international sample.

To this end, we follow the regression decomposition approach of Anginer and Yildizhan (2014), estimating the following regression using a 48-month rolling window:

$$
\text { CHS }_{i, t}=a_{i, t}+\beta_{i, t} M C H S_{t}+\varepsilon_{i, t}
$$

where $C H S_{i, t}$ is the default risk measure for firm $i$ in month $t$ and $M C H S_{t}$ is the median crosssectional value of CHS in month $t$. The slope regression coefficient $\beta_{i, t}$ is a proxy for the systematic default risk of firm $i$ in month $t$, since it captures the sensitivity of the firm's default risk to changes in aggregate default risk. Moreover, the idiosyncratic default risk component of firm $i$ in month $t$ is given by the sum of the intercept and the corresponding residual value. We perform this decomposition among firms in both the C6 and the C14 countries.

Having computed these systematic and idiosyncratic default risk measures, we alternatively sort firms on the basis of each measure, classify them into portfolios and compute their post-ranking returns. The results are presented in the Supplementary Appendix. Since we use a window of 48 months to estimate $\beta_{i, t}$, the test period now becomes 2004-2014. 
In line with the arguments of Anginer and Yildizhan (2014), we find that the systematic component of default risk carries a significant premium. In particular, the spread strategy that is long the quintile portfolio with the highest systematic default risk firms and short the quintile portfolio with the lowest systematic default risk firms, Q5-Q1, yields a premium of $10.65 \%(10.29 \%)$ p.a. in the case of value-weighted (equally-weighted) portfolios in the C6 countries. Similar is the evidence in the $\mathrm{C} 14$ countries, although the premium is marginally insignificant in the case of value-weighted portfolios. Adjusting for market, size, value, and momentum factor exposures, the Q5-Q1 strategy yields a significant FFC alpha in most of the cases examined, and hence the magnitude of the default risk premium remains intact.

To the contrary, sorting stocks on the basis of their idiosyncratic default risk estimates, we do not find a positive relation between this measure of default risk and post-ranking portfolio returns. The spread strategy between the highest and the lowest idiosyncratic default risk quintile portfolios, Q5-Q1, yields a premium that is close to zero and insignificant in both the C6 and the $\mathrm{C} 14$ countries. Using the FFC model to adjust portfolio returns, we get very similar results. In sum, we find that consistent with the predictions of standard asset pricing theory, the idiosyncratic component of firms' default risk is not priced in the cross-section of stock returns.

\section{Conclusions}

Motivated by the lack of consensus on the pricing of default risk in the US market, this study examines this issue in a large sample of firms from 14 developed (ex US) markets and makes a number of contributions. First, we construct the largest dataset of non-US firm bankruptcies that has been examined in the literature. Second, utilizing this dataset, we estimate OOS firm default probabilities from country- and bankruptcy law-specific hazard models à la Campbell et al. (2008), and show that this default risk proxy has a clearly superior ability to forecast bankruptcies relative to Merton's (1974) MDD measure, both in-sample and out-of-sample. 
Third, we find a significant default risk premium in our international sample. The positive relation between default risk and stock returns is robust to different portfolio weighting schemes, data filters, and holding period definitions, and remains intact after controlling for a series of firm characteristics. Fourth, we find that the systematic component of default risk drives this positive relation rather than the idiosyncratic one.

Our results are in contrast to the conclusion of EGZ and GPS that a default risk puzzle exists in international markets too, which is derived on the basis of MDD and Moody's KMV EDF, respectively. Showing that MDD is not a sufficient statistic for default probability and that it is inferior to CHS for bankruptcy forecasting, we derive a different conclusion because CHS disagrees with MDD predominantly on the identification of the lowest default risk firms.

Finally, our international dataset allows us to examine what are the country-level characteristics that drive the default premium. To this end, we find that the premium is relatively higher in countries where creditor protection is stronger and shareholder bargaining power is lower, in line with the arguments of Favara et al. (2012). Furthermore, consistent with the shareholder advantage hypothesis of Garlappi et al. (2008), we find that the default risk premium is more pronounced among firms with high asset tangibility.

Echoing the concerns of Chava and Purnanandam (2010), our results indicate that the distress anomaly could be specific to the US market. Therefore, as the quality of international bankruptcy filing data is bound to improve in the future, there is scope for expanding the cross-section of firms by considering less developed markets as well as extending the time period to study the behavior of the default risk premium across different economic conditions. Another important research direction is to delve further into the drivers of the default risk premium outside the US market. Of particular interest is the question whether proposed explanations for the anomalous returns of US distressed stocks, such as differences in corporate liquidity (Medhat, 2014) and lottery-like payoffs of distressed stocks (Conrad et al., 2014) can also help us understand the behavior of distressed stocks in non-US markets. 


\section{References}

Altman, E. I., 1968. Financial ratios, discriminant analysis and the prediction of corporate bankruptcy. The Journal of Finance 23, 589-609.

Anginer, D., Yildizhan, C., 2014. Is there a distress risk anomaly? Corporate bond spreads as a proxy for default risk, University of Michigan Working Paper Series.

Avramov, D., Chordia, T., Jostova, G., Philipov, A., 2009. Credit ratings and the cross-section of stock returns. Journal of Financial Markets 12, 469-499.

Bharath, S. T., Shumway, T., 2008. Forecasting default with the Merton distance-to-default model. Review of Financial Studies 21, 1339-1369.

Black, F., Scholes, M., 1973. The pricing of options and corporate liabilities. Journal of Political Economy 81, 637-659.

Blume, M. E., Stambaugh, R. F., 1983. Biases in computed returns: An application to the size effect. Journal of Financial Economics 12, 387-404.

Campbell, J. Y., Hilscher, J., Szilagyi, J., 2008. In search of distress risk. The Journal of Finance 63, 2899-2939.

Campbell, J. Y., Hilscher, J., Szilagyi, J., 2011. Predicting financial distress and the performance of distressed stocks. Journal of Investment Management 9, 14-34.

Chan, K., Chen, N., 1991. Structural and return characteristics of small and large firms. The Journal of Finance 46, 1467-1484.

Chava, S., Jarrow, R. A., 2004. Bankruptcy prediction with industry effects. Review of Finance $8,537-569$.

Chava, S., Purnanandam, A. K., 2010. Is default risk negatively related to stock returns? Review of Financial Studies 23, 2523-2559.

Cohen, R. B., Polk, C., Vuolteenaho, T., 2003. The value spread. Journal of Finance 58, 609641.

Conrad, J., Kapadia, N., Xing, Y., 2014. Death and jackpot: Why do individual investors hold overpriced stocks? Journal of Financial Economics 113, 455-475.

Correia, M., Richardson, S., Tuna, I., 2012. Value investing in credit markets. Review of Accounting Studies 17, 572-609.

Crosbie, P., Bohn, J., 2003. Modeling default risk, available from: www.ma.hw.ac.uk/ mcneil/ F79CR/Crosbie_Bohn.pdf.

Da, Z., Gao, P., 2010. Clientele change, liquidity shock, and the return on financially distressed stocks. Journal of Financial and Quantitative Analysis 45, 27-48.

Davydenko, S. A., 2008. When do firms default? A study of the default boundary, University of Toronto Working Paper Series.

DeFond, M., Hung, M., Trezevant, R., 2007. Investor protection and the information content of annual earnings announcements: International evidence. Journal of Accounting and Economics 43, 37-67.

Dichev, I. D., 1998. Is the risk of bankruptcy a systematic risk? The Journal of Finance 53, 1131-1147. 
Djankov, S., Hart, O., McLiesh, C., Shleifer, A., 2008. Debt enforcement around the world. Journal of Political Economy 116, 1105-1150.

Eisdorfer, A., Goyal, A., Zhdanov, A., 2013. Distress anomaly and shareholder risk: International evidence. University of Connecticut Working Paper Series.

Fama, E. F., French, K. R., 1996. Multifactor explanations of asset pricing anomalies. The Journal of Finance 51, 55-84.

Fama, E. F., French, K. R., 2012. Size, value, and momentum in international stock returns. Journal of Financial Economics 105, 457-472.

Favara, G., Schroth, E., Valta, P., 2012. Strategic default and equity risk across countries. The Journal of Finance 67, 2051-2095.

Foster, F. D., Smith, T., Whaley, R. E., 1997. Assessing the goodness-of-fit of asset pricing models: The distribution of the maximal $\mathrm{R}^{2}$. The Journal of Finance 52, 591-607.

Friewald, N., Wagner, C., Zechner, J., 2014. The cross-section of credit risk premia and equity returns. The Journal of Finance 69, 2419-2469.

Gao, P., Parsons, C. A., Shen, J., 2015. The global relation between financial distress and equity returns, University of Notre Dame Working Paper Series.

Garlappi, L., Shu, T., Yan, H., 2008. Default risk, shareholder advantage and stock returns. Review of Financial Studies 21, 2743-2778.

Garlappi, L., Yan, H., 2011. Financial distress and the cross-section of equity returns. The Journal of Finance 66, 789-822.

George, T. J., Hwang, C.-Y., 2010. A resolution of the distress risk and leverage puzzles in the cross section of stock returns. Journal of Financial Economics 96, 56-79.

Griffin, J., Lemmon, M., 2002. Book to market equity, distress risk, and stock returns. The Journal of Finance 57, 2317-2336.

Hackbarth, D., Haselmann, R., Schoenherr, D., 2015. Financial distress, stock returns, and the 1978 Bankruptcy Reform Act. Review of Financial Studies 28, 1810-1847.

Hillegeist, S., Keating, E., Cram, D., Lundstedt, K., 2004. Assessing the probability of default. Review of Accounting Studies 9, 5-34.

Hilscher, J., Wilson, M., 2015. Credit ratings and credit risk: Is one measure enough?. Management Science, forthcoming.

Hofstede, G., 2001. Culture's consequences: Comparing values, behaviors, institutions, and organizations across nations. 2nd edition, Sage Publications, Beverly Hills, CA.

Kaiser, K. M. J., 1996. European bankruptcy laws: Implications for corporations facing financial distress. Financial Management 25, 67-85.

Kapadia, N., 2011. Tracking down distress risk. Journal of Financial Economics 102, 167-182.

La Porta, R., Lopez-de Silanes, F., Shleifer, A., Vishny, R. W., 1998. Law and finance. Journal of Political Economy 106, 1113-1155.

Lehman, B.N., 1990. Fads, martingales, and market efficiency. Quarterly Journal of Economics $105,1-28$.

Lo, A. W., MacKinlay, A. C., 2001, A non-random walk down Wall Street, Princeton University Press, New Jersey. 
Medhat, M., 2014. Liquidity risk and distressed equity, Copenhagen Business School Working Paper.

Merton, R. C., 1974. On the pricing of corporate debt: The risk structure of interest rates. The Journal of Finance 29, 449-470.

Moody's Investor Services, 2011. Corporate default and recovery rates 1920-2010, available from efinance.org.cn/cn/FEben/Corporate\%20Default\%20and\%20Recovery\%20Rates, 19202010.pdf.

Newey, W. K., West, K. D., 1987. A simple positive-definite heteroscedasticity and autocorrelation consistent covariance matrix. Econometrica 55, 703-708.

O'Doherty, M. S., 2012. On the conditional risk and performance of financially distressed stocks. Management Science 58, 1502-1520.

Ohlson, J. A., 1980. Financial ratios and the probabilistic prediction of bankruptcy. Journal of Accounting Research 18, 109-131.

Pinkowitz, L., Williamson, R., 2001. Bank power and cash holdings: Evidence from Japan. Review of Financial Studies 14, 1059-1082.

Shumway, T., 2001. Forecasting bankruptcy more accurately: A simple hazard model. Journal of Business 74, 101-124.

Vassalou, M., Xing, Y., 2004. Default risk in equity returns. The Journal of Finance 59, 831868.

Wood, P. R., 2007. Principles of international insolvency. Sweet \& Maxwell, London. 
Table 1

Number and Proportion of Bankruptcies per Country and Year

This table reports the total number of bankruptcies (\#B), the total number of active firms with complete data (\#ALL) and the proportion of active firms with complete data that went bankrupt (\%) each year in our sample period and over the full sample period (1992-2013). This information is reported for Australia, Canada, France, Germany, Japan and the UK (the C6 countries). In the last column, we provide the corresponding information for the pooled sample of all C6 countries.

\begin{tabular}{|c|c|c|c|c|c|c|c|c|c|c|c|c|c|c|c|c|c|c|c|c|c|}
\hline \multirow[b]{2}{*}{ Year } & \multicolumn{3}{|c|}{ Australia } & \multicolumn{3}{|c|}{ Canada } & \multicolumn{3}{|c|}{ France } & \multicolumn{3}{|c|}{ Germany } & \multicolumn{3}{|c|}{ Japan } & \multicolumn{3}{|c|}{ United Kingdom } & \multicolumn{3}{|c|}{ All countries } \\
\hline & $\# B$ & \#ALL & $\%$ & $\# B$ & $\# A L L$ & $\%$ & $\# B$ & $\# A L L$ & $\%$ & $\# B$ & \#ALL & $\%$ & $\# B$ & \#ALL & $\%$ & $\# B$ & \#ALL & $\%$ & $\# B$ & $\# A L L$ & $\%$ \\
\hline 1992 & & & & & & & & & & & & & & & & 14 & 1,176 & 1.19 & 14 & 1,176 & 1.19 \\
\hline 1993 & & & & & & & 2 & 463 & 0.43 & & & & 2 & 1,798 & 0.11 & 5 & 1,166 & 0.43 & 9 & 3,427 & 0.26 \\
\hline 1994 & & & & & & & 0 & 468 & 0.00 & & & & 0 & 1,889 & 0.00 & 3 & 1,175 & 0.26 & 3 & 3,532 & 0.08 \\
\hline 1995 & & & & & & & 1 & 482 & 0.21 & 1 & 342 & 0.29 & 1 & 2,012 & 0.05 & 4 & 1,200 & 0.33 & 7 & 4,036 & 0.17 \\
\hline 1996 & 1 & 256 & 0.39 & 0 & 383 & 0.00 & 4 & 472 & 0.85 & 2 & 351 & 0.57 & 1 & 2,080 & 0.05 & 8 & 1,215 & 0.66 & 16 & 4,757 & 0.34 \\
\hline 1997 & 1 & 304 & 0.33 & 2 & 413 & 0.48 & 1 & 536 & 0.19 & 1 & 410 & 0.24 & 8 & 2,136 & 0.37 & 6 & 1,375 & 0.44 & 19 & 5,174 & 0.37 \\
\hline 1998 & 2 & 328 & 0.61 & 0 & 441 & 0.00 & 2 & 659 & 0.30 & 1 & 477 & 0.21 & 7 & 2,311 & 0.30 & 11 & 1,496 & 0.74 & 23 & 5,712 & 0.40 \\
\hline 1999 & 1 & 362 & 0.28 & 4 & 579 & 0.69 & 1 & 770 & 0.13 & 4 & 539 & 0.74 & 3 & 2,861 & 0.10 & 16 & 1,464 & 1.09 & 29 & 6,576 & 0.44 \\
\hline 2000 & 3 & 496 & 0.60 & 4 & 748 & 0.54 & 1 & 845 & 0.12 & 3 & 640 & 0.47 & 11 & 2,990 & 0.37 & 7 & 1,383 & 0.51 & 29 & 7,101 & 0.41 \\
\hline 2001 & 8 & 734 & 1.09 & 3 & 875 & 0.34 & 3 & 879 & 0.34 & 16 & 742 & 2.16 & 11 & 3,047 & 0.36 & 22 & 1,347 & 1.63 & 63 & 7,625 & 0.83 \\
\hline 2002 & 6 & 1,214 & 0.49 & 3 & 926 & 0.32 & 10 & 870 & 1.15 & 29 & 776 & 3.74 & 29 & 3,174 & 0.91 & 24 & 1,336 & 1.80 & 101 & 8,297 & 1.22 \\
\hline 2003 & 6 & 1,243 & 0.48 & 1 & 1,070 & 0.09 & 10 & 824 & 1.21 & 16 & 744 & 2.15 & 18 & 3,240 & 0.56 & 16 & 1,301 & 1.23 & 67 & 8,422 & 0.80 \\
\hline 2004 & 5 & 1,254 & 0.40 & 4 & 1,197 & 0.33 & 4 & 776 & 0.52 & 9 & 705 & 1.28 & 11 & 3,293 & 0.33 & 10 & 1,267 & 0.79 & 43 & 8,493 & 0.51 \\
\hline 2005 & 6 & 1,364 & 0.44 & 1 & 1,336 & 0.07 & 3 & 735 & 0.41 & 4 & 689 & 0.58 & 8 & 3,404 & 0.24 & 9 & 1,342 & 0.67 & 31 & 8,869 & 0.35 \\
\hline 2006 & 7 & 1,485 & 0.47 & 6 & 1,964 & 0.31 & 2 & 747 & 0.27 & 6 & 705 & 0.85 & 2 & 3,523 & 0.06 & 7 & 1,493 & 0.47 & 30 & 9,917 & 0.30 \\
\hline 2007 & 7 & 1,609 & 0.44 & 5 & 2,328 & 0.21 & 3 & 787 & 0.38 & 13 & 766 & 1.70 & 6 & 3,651 & 0.16 & 5 & 1,622 & 0.31 & 39 & 10,763 & 0.36 \\
\hline 2008 & 20 & 1,747 & 1.14 & 7 & 2,480 & 0.28 & 0 & 803 & 0.00 & 9 & 832 & 1.08 & 32 & 3,678 & 0.87 & 33 & 1,663 & 1.98 & 101 & 11,203 & 0.90 \\
\hline 2009 & 22 & 1,795 & 1.23 & 6 & 2,531 & 0.24 & 8 & 782 & 1.02 & 24 & 832 & 2.88 & 32 & 3,600 & 0.89 & 38 & 1,594 & 2.38 & 130 & 11,134 & 1.17 \\
\hline 2010 & 4 & 1,767 & 0.23 & 6 & 2,554 & 0.23 & 7 & 758 & 0.92 & 10 & 817 & 1.22 & 5 & 3,533 & 0.14 & 13 & 1,507 & 0.86 & 45 & 10,935 & 0.41 \\
\hline 2011 & 9 & 1,802 & 0.50 & 10 & 2,672 & 0.37 & 9 & 758 & 1.19 & 3 & 814 & 0.37 & 2 & 3,560 & 0.06 & 10 & 1,592 & 0.63 & 43 & 11,198 & 0.38 \\
\hline 2012 & 10 & 1,845 & 0.54 & 11 & 2,777 & 0.40 & 8 & 736 & 1.09 & 10 & 791 & 1.26 & 4 & 3,534 & 0.11 & 17 & 1,562 & 1.09 & 60 & 11,244 & 0.53 \\
\hline 2013 & 8 & 1,805 & 0.44 & 15 & 2,715 & 0.55 & 1 & 701 & 0.14 & 4 & 754 & 0.53 & 3 & 3,446 & 0.09 & 11 & 1,472 & 0.75 & 42 & 10,894 & 0.39 \\
\hline $1992-2013$ & 126 & 21,410 & 0.59 & 88 & 27,989 & 0.31 & 80 & 14,850 & 0.54 & 165 & 12,729 & 1.30 & 196 & 62,760 & 0.31 & 289 & 30,748 & 0.94 & 944 & 170,484 & 0.55 \\
\hline
\end{tabular}


Table 2

\section{Summary Statistics}

This table presents summary statistics (means, medians and standard deviations) for each of the following variables: NIMTA (net income scaled by the sum of market value of equity and total liabilities), TLMTA (total liabilities scaled by the sum of market value of equity and total liabilities), EXRET (monthly log stock return of a firm minus that of the index of the market in which the firm is headquartered), RSIZE (log ratio of a firm's market value to the sum of market values for all firms in the same market and month), SIGMA (annualized standard deviation of a firm's daily log stock return in the prior three months), CASHMTA (ratio of cash and short-term assets to the sum of market value of equity and total liabilities), MB (market-to-book value ratio) and PRICE (log stock price). In each panel, the statistics are reported for active firms (act) as well as for bankrupt firms (bank) in the month prior to their filing $(t-1)$. The statistics are reported for Australia, Canada, France, Germany, Japan and the UK (the C6 countries) over the period 1992-2013. In Panel G, we also provide the corresponding statistics for the pooled sample of firms in all C6 countries.

\begin{tabular}{|c|c|c|c|c|c|c|c|c|c|c|c|c|c|c|c|c|}
\hline & \multicolumn{2}{|c|}{ NIMTA } & \multicolumn{2}{|c|}{ TLMTA } & \multicolumn{2}{|c|}{ EXRET } & \multicolumn{2}{|c|}{ RSIZE } & \multicolumn{2}{|c|}{ SIGMA } & \multicolumn{2}{|c|}{ CASHMTA } & \multicolumn{2}{|c|}{$\mathrm{MB}$} & \multicolumn{2}{|c|}{ PRICE } \\
\hline & act & bank & act & bank & act & bank & act & bank & act & bank & act & bank & act & bank & act & bank \\
\hline \multicolumn{17}{|c|}{ Panel A: Australia } \\
\hline Mean & -0.10 & -0.25 & 0.25 & 0.63 & 0.00 & -0.11 & -10.16 & -11.59 & 0.72 & 1.12 & 0.17 & 0.14 & 2.12 & 1.50 & -0.96 & -1.69 \\
\hline Median & -0.02 & -0.14 & 0.17 & 0.71 & -0.01 & -0.08 & -10.47 & -11.92 & 0.68 & 1.09 & 0.07 & 0.05 & 1.45 & 0.56 & -0.92 & -1.86 \\
\hline St.Dev & 0.24 & 0.31 & 0.24 & 0.24 & 0.16 & 0.17 & 2.03 & 1.39 & 0.39 & 0.43 & 0.26 & 0.23 & 1.80 & 2.11 & 1.20 & 1.15 \\
\hline \multicolumn{17}{|c|}{ All firm/months ( $N=256,918) ;$ Bankruptcy Group ( $N=126)$} \\
\hline \multicolumn{17}{|c|}{ Panel B: Canada } \\
\hline Mean & -0.10 & -0.39 & 0.26 & 0.64 & 0.00 & -0.18 & -10.46 & -12.46 & 0.89 & 1.59 & 0.14 & 0.15 & 2.35 & 2.25 & 0.08 & -1.25 \\
\hline Median & -0.02 & -0.29 & 0.17 & 0.74 & -0.01 & -0.25 & -10.50 & -12.92 & 0.80 & 1.51 & 0.05 & 0.05 & 1.64 & 0.75 & 0.21 & -1.51 \\
\hline St.Dev & 0.25 & 0.42 & 0.26 & 0.25 & 0.18 & 0.25 & 2.29 & 2.10 & 0.56 & 0.64 & 0.22 & 0.24 & 1.97 & 2.58 & 1.43 & 1.23 \\
\hline \multicolumn{17}{|c|}{ All firm/months $(N=335,867) ;$ Bankruptcy Group $(N=88)$} \\
\hline \multicolumn{17}{|c|}{ Panel C: France } \\
\hline Mean & 0.01 & -0.07 & 0.47 & 0.70 & 0.00 & -0.04 & -9.52 & -11.93 & 0.44 & 0.67 & 0.10 & 0.07 & 2.06 & 2.67 & 2.86 & 1.95 \\
\hline Median & 0.02 & -0.06 & 0.47 & 0.78 & -0.05 & -0.04 & -9.78 & -12.20 & 0.39 & 0.60 & 0.07 & 0.03 & 1.56 & 1.36 & 2.93 & 1.67 \\
\hline St.Dev & 0.06 & 0.10 & 0.25 & 0.27 & 0.10 & 0.13 & 2.14 & 1.33 & 0.23 & 0.32 & 0.10 & 0.11 & 1.57 & 2.40 & 0.91 & 0.83 \\
\hline \multicolumn{17}{|c|}{ All firm/months $(N=178,198) ;$ Bankruptcy Group $(N=80)$} \\
\hline \multicolumn{17}{|c|}{ Panel D: Germany } \\
\hline Mean & -0.02 & -0.15 & 0.44 & 0.76 & -0.01 & -0.07 & -9.41 & -11.67 & 0.50 & 1.10 & 0.12 & 0.16 & 2.19 & 1.46 & 2.28 & 1.26 \\
\hline Median & 0.01 & -0.07 & 0.43 & 0.85 & -0.01 & -0.12 & -9.56 & -11.92 & 0.43 & 1.10 & 0.06 & 0.06 & 1.67 & 0.54 & 2.40 & 1.07 \\
\hline St.Dev & 0.14 & 0.27 & 0.27 & 0.23 & 0.12 & 0.19 & 1.99 & 1.50 & 0.32 & 0.46 & 0.17 & 0.22 & 1.69 & 2.00 & 1.06 & 0.85 \\
\hline \multicolumn{17}{|c|}{ All firms/months ( $N=152,742) ;$ Bankruptcy Group $(N=165)$} \\
\hline \multicolumn{17}{|c|}{ Panel E: Japan } \\
\hline Mean & 0.01 & -0.02 & 0.54 & 0.82 & 0.00 & -0.02 & -9.95 & -11.33 & 0.41 & 0.74 & 0.17 & 0.11 & 1.30 & 1.26 & 6.36 & 5.90 \\
\hline Median & 0.02 & -0.01 & 0.56 & 0.91 & -0.01 & -0.05 & -10.09 & -11.52 & 0.37 & 0.77 & 0.13 & 0.08 & 1.02 & 0.68 & 6.35 & 5.59 \\
\hline St.Dev & 0.04 & 0.05 & 0.23 & 0.20 & 0.09 & 0.15 & 1.56 & 1.15 & 0.19 & 0.25 & 0.13 & 0.10 & 0.94 & 1.30 & 0.68 & 0.74 \\
\hline \multicolumn{17}{|c|}{ All firms/months $(N=753,115) ;$ Bankruptcy Group $(N=196)$} \\
\hline \multicolumn{17}{|c|}{ Panel F: United Kingdom } \\
\hline Mean & -0.02 & -0.17 & 0.38 & 0.73 & 0.00 & -0.10 & -9.84 & -12.33 & 0.39 & 0.72 & 0.10 & 0.11 & 2.31 & 1.87 & 4.36 & 3.13 \\
\hline Median & 0.02 & -0.12 & 0.35 & 0.80 & -0.01 & -0.13 & -9.94 & -12.33 & 0.35 & 0.73 & 0.05 & 0.04 & 1.63 & 0.56 & 4.52 & 3.27 \\
\hline St.Dev & 0.14 & 0.22 & 0.24 & 0.19 & 0.11 & 0.16 & 2.03 & 1.18 & 0.22 & 0.28 & 0.15 & 0.19 & 1.91 & 2.51 & 1.01 & 0.75 \\
\hline \multicolumn{17}{|c|}{ All firms/months ( $N=368,944) ;$ Bankruptcy Group ( $N=289)$} \\
\hline \multicolumn{17}{|c|}{ Panel G: All Countries } \\
\hline Mean & -0.03 & -0.16 & 0.41 & 0.73 & 0.00 & -0.08 & -9.96 & -11.88 & 0.54 & 0.92 & 0.14 & 0.12 & 1.89 & 1.72 & 3.44 & 2.22 \\
\hline Median & 0.01 & -0.07 & 0.40 & 0.81 & -0.01 & -0.09 & -10.08 & -12.08 & 0.43 & 0.84 & 0.09 & 0.05 & 1.32 & 0.62 & 4.01 & 2.30 \\
\hline St.Dev & 0.16 & 0.26 & 0.27 & 0.23 & 0.13 & 0.18 & 1.95 & 1.43 & 0.38 & 0.47 & 0.17 & 0.19 & 1.63 & 2.20 & 2.95 & 2.68 \\
\hline All firms & 045,7 & 784); $B a$ & ruptcy & Sroup & $V=944$ ) & & & & & & & & & & & \\
\hline
\end{tabular}




\section{Table 3}

\section{Logit Regressions of Bankruptcy Indicator on 12-month Lagged Predictor Variables}

This table reports results from country-specific LOGIT regressions of a bankruptcy indicator on a set of predictors (listed and defined below) that are lagged by 12 months. NIMTA is net income scaled by the sum of the market value of equity and total liabilities. TLMTA is total liabilities scaled by the sum of the market value of equity and total liabilities. EXRET is the monthly log stock return of a firm minus that of the index of the market in which the firm is headquartered. RSIZE is the log ratio of a firm's market value to the sum of market values for all firms in the same market and month. SIGMA is the annualized standard deviation of a firm's daily log stock returns in the prior three months. CASHMTA is the ratio of cash and short-term assets to the sum of the market value of equity and total liabilities. MB is the market-to-book value ratio, whereas PRICE is the log stock price. Estimated coefficients are in bold, whereas $z$-statistics, which are constructed using heteroscedasticityrobust standard errors, are reported in square brackets. The column titled 'LR test' reports the results from a likelihood ratio test on whether the coefficients of each predictor differ significantly across the six countries. The bold number in the last column is twice the difference between the log-likelihood of a pooled LOGIT model including country-specific interaction terms on all predictors (including constants) except for the variable in the row in which the statistic is reported (restricted model), and that from a pooled LOGIT model including all country interactions terms (unrestricted model). The $p$-value associated with the LR test statistic is shown below in parenthesis. ${ }^{* * *}, * *$ and $*$ denote statistical significance at $1 \%, 5 \%$ and $10 \%$ levels, respectively.

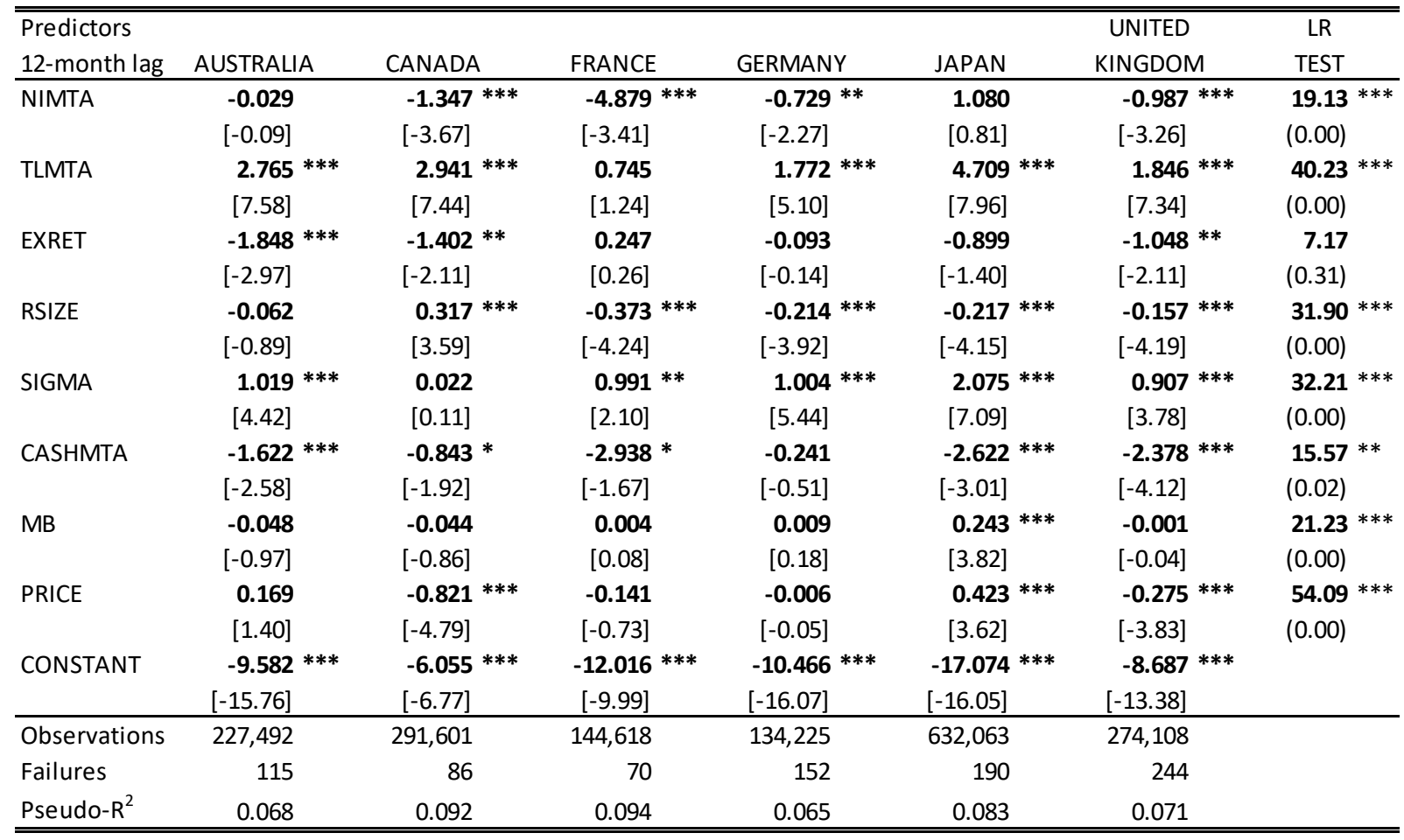




\section{Table 4}

\section{Logit Regressions including Merton's Distance-to-Default and Accuracy Ratios}

This table reports selected results from country-specific LOGIT regressions of a bankruptcy indicator on sets of predictors that are lagged by 12 months. As exogenous variables, the models use either $(i)$ only Merton's (1974) Distance-to-Default (MDD) in Panel A, or (ii) MDD together with the Campbell et al. (2008, CHS) default risk indicators, namely NIMTA, TLMTA, EXRET, RSIZE, SIGMA, CASHMTA, MB and PRICE (see the caption of Table 3 for a description of these variables) in Panel $\mathrm{B}$ or (iii) only the CHS default risk indicators in Panel C. The LOGIT models in Panels A-C are estimated using only the firm-month observations and failures for which both MDD and the CHS default risk indicators are available. Reported results refer to the slope coefficient of MDD (in bold) and the associated z-statistic, computed using heteroscedasticity-robust standard errors (in square brackets) where applicable, as well as the pseudo $\mathrm{R}^{2}$ of each model. To construct the MDD measure, we follow the methodology of Vassalou and Xing (2004) (see Section 3.1 for details). ***, ** and * denote statistical significance at $1 \%, 5 \%$ and $10 \%$ levels, respectively. Panel D reports the average accuracy ratios of the CHS and MDD default risk measures for each of the C6 countries. The accuracy ratio is given by the ratio of each measure's area under curve divided by the area under curve of the "perfect foresight measure", which could ex ante assign the highest default risk rank exactly to those firms that subsequently defaulted. We follow the methodology of Vassalou and Xing (2004) to compute areas under curve (see Section 3.3 for details).

\begin{tabular}{|c|c|c|c|c|c|c|}
\hline Predictors & & & & & & UNITED \\
\hline 12-month lag & AUSTRALIA & CANADA & FRANCE & GERMANY & JAPAN & KINGDOM \\
\hline \multicolumn{7}{|c|}{ Panel A : Merton (1974) Distance-to-Default } \\
\hline \multirow[t]{2}{*}{ MDD } & $2.739 * * *$ & $2.416 * * *$ & $2.955 * * *$ & $2.905 * * *$ & $3.104 * * *$ & $2.617 * * *$ \\
\hline & [9.33] & {$[6.61]$} & [7.08] & [14.36] & [16.43] & [13.08] \\
\hline Pseudo- $R^{2}$ & 0.044 & 0.033 & 0.047 & 0.066 & 0.041 & 0.039 \\
\hline \multicolumn{7}{|c|}{ Panel B: Merton (1974) Distance-to-Default + CHS Default Risk Indicators } \\
\hline \multirow[t]{2}{*}{ MDD } & $0.991 *$ & 0.251 & 1.225 & $1.606 * * *$ & $0.783 * *$ & 0.402 \\
\hline & [1.84] & {$[0.44]$} & [1.49] & [4.44] & {$[2.45]$} & [1.17] \\
\hline Pseudo- $R^{2}$ & 0.079 & 0.078 & 0.093 & 0.084 & 0.085 & 0.079 \\
\hline \multicolumn{7}{|c|}{ Panel C: CHS Default Risk Indicators } \\
\hline Pseudo- $R^{2}$ & 0.077 & 0.078 & 0.089 & 0.073 & 0.083 & 0.078 \\
\hline Observations & 179,723 & 215,544 & 102,149 & 104,591 & 485,069 & 180,814 \\
\hline Failures & 76 & 50 & 39 & 148 & 169 & 156 \\
\hline \multicolumn{7}{|c|}{ Panel D: Accuracy Ratios } \\
\hline $\mathrm{CHS}$ & 0.651 & 0.720 & 0.581 & 0.693 & 0.467 & 0.750 \\
\hline MDD & 0.571 & 0.665 & 0.459 & 0.618 & 0.312 & 0.671 \\
\hline
\end{tabular}




\section{Table 5}

\section{Out-of-Sample Global Default Risk Portfolios}

This table reports average excess returns, CAPM alphas, and four-factor alphas from the Fama-French-Carhart asset pricing model (FFC alphas) for portfolios constructed on the basis of out-of-sample (OOS) estimates of the Campbell et al. (2008, CHS) default risk measure. We construct these portfolios for stocks in the C6 countries (Australia, Canada, France, Germany, Japan and the United Kingdom; Panel A) and the C14 countries (the C6 countries plus Denmark, Finland, Hong Kong, New Zealand, Portugal, Spain, Sweden and Taiwan; Panel B). To estimate OOS CHS measures, a LOGIT model is recursively run for each of the C6 countries; see Section 3 . For the countries that feature too few bankruptcies, we run recursively a LOGIT model for each bankruptcy law regime. We consider four bankruptcy law regimes: Common Law (Australia, Canada, Hong Kong, New Zealand and the U.K.), Napoleonic (France, Spain and Portugal), Roman-Germanic (Denmark, Finland, Germany and Sweden) and Mixed (Japan and Taiwan). The recursive LOGIT estimations start with an initial window including data up to December 1999. At the end of December of year $t$-1, we sort stocks in ascending order on the basis of their OOS CHS default risk estimates and allocate them into decile and quintile portfolios. We form the spread strategy Q5-Q1 that is long the quintile portfolio with the highest default risk stocks (Q5) and short the quintile portfolio with the lowest default risk stocks (Q1). We also form the spread strategy P10-P1 that is long the decile portfolio with the highest default risk stocks (P10) and short the decile portfolio with the lowest default risk stocks $(\mathrm{P} 1)$. We exclude stocks whose price or market capitalization is below the $5^{\text {th }}$ percentile of the corresponding country-month distribution at the portfolio formation date. Portfolios are held from February of year $t$ to January of year $t+1$, at which point they are rebalanced, allowing for a one month gap between the portfolio formation date and the beginning of the holding period. Returns are calculated in USD terms and they are reported for value-weighted (vw) and equally-weighted (ew) portfolios. Average excess portfolio returns and alphas are annualized and bolded; their associated t-statistics are reported in square brackets. We use the Developed Markets Global ex US FamaFrench market, size, value, and momentum factors, sourced from K. French's online data library; see Fama and French (2012, p. 459-460) for their construction details. The lower part of each panel reports the (equally-weighted) average number of firms per portfolio, stocks' average standard deviation of returns (SIGMA), their average log relative size (RSIZE) and their average OOS CHS default probability estimate. The examined period is $2000-2014 . * * *, * *$ and $*$ denote statistical significance at $1 \%, 5 \%$ and $10 \%$ levels, respectively.

\begin{tabular}{|c|c|c|c|c|c|c|c|c|c|c|}
\hline & & \multicolumn{7}{|c|}{ Deciles } & \multirow[b]{2}{*}{ Q5-Q1 } & \multirow[b]{2}{*}{ P10-P1 } \\
\hline & & 1 & 2 & $3-4$ & $5-6$ & $7-8$ & 9 & 10 & & \\
\hline \multicolumn{11}{|c|}{ Panel A: C6 Countries } \\
\hline \multirow[t]{4}{*}{ Excess return } & vw & -2.66 & -3.01 & 1.06 & 2.54 & 6.48 & 9.75 & 11.80 & $13.86 * * *$ & $14.46 * *$ \\
\hline & & {$[-0.51]$} & {$[-0.48]$} & [0.19] & {$[0.44]$} & [1.01] & {$[1.35]$} & {$[1.35]$} & {$[2.71]$} & {$[2.26]$} \\
\hline & ew & 4.49 & 3.37 & 5.32 & 6.98 & 8.91 & 10.48 & $17.86 * *$ & $10.24 * *$ & $13.37 * *$ \\
\hline & & {$[0.77]$} & {$[0.51]$} & [0.79] & {$[0.96]$} & [1.19] & [1.37] & [2.05] & [2.43] & [2.41] \\
\hline \multirow[t]{4}{*}{ CAPM alpha } & vw & $-5.11 *$ & $-6.16 * *$ & $-2.55 * * *$ & -1.21 & 2.49 & 5.52 & 7.48 & $12.41 * *$ & $12.59 * *$ \\
\hline & & {$[-1.96]$} & {$[-2.28]$} & {$[-3.42]$} & {$[-0.95]$} & [1.12] & {$[1.64]$} & {$[1.44]$} & [2.47] & [2.11] \\
\hline & ew & 2.30 & 0.39 & 1.65 & 2.95 & 4.90 & $6.54 *$ & $13.88 * * *$ & $8.87 * *$ & $11.58 * *$ \\
\hline & & [0.58] & [0.09] & {$[0.52]$} & [0.98] & [1.54] & {$[1.94]$} & {$[2.63]$} & {$[2.43]$} & [2.32] \\
\hline \multirow[t]{4}{*}{ FFC alpha } & vw & $-3.82 * *$ & $-5.88 * * *$ & $-1.77 * *$ & -1.14 & -0.30 & 1.01 & 5.68 & $8.13 * *$ & $9.50 *$ \\
\hline & & {$[-2.07]$} & {$[-2.74]$} & {$[-2.14]$} & {$[-1.20]$} & {$[-0.13]$} & {$[0.43]$} & {$[1.20]$} & {$[2.16]$} & {$[1.67]$} \\
\hline & ew & 0.37 & -1.40 & -0.09 & 1.78 & 3.20 & $5.29 * *$ & $13.52 * * *$ & $9.92 * * *$ & $13.15 * * *$ \\
\hline & & [0.14] & {$[-0.53]$} & {$[-0.05]$} & [0.91] & [1.55] & {$[2.55]$} & {$[3.88]$} & [2.95] & [3.00] \\
\hline average \# of firms & & 823 & 823 & 1646 & 1646 & 1646 & 823 & 823 & & \\
\hline average sigma & & 0.40 & 0.47 & 0.51 & 0.53 & 0.56 & 0.60 & 0.72 & & \\
\hline average RSIZE & & -9.54 & -9.73 & -9.57 & -9.61 & -10.05 & -10.66 & -11.36 & & \\
\hline average $\mathrm{CHS}$ & & $0.00 \%$ & $0.01 \%$ & $0.02 \%$ & $0.04 \%$ & $0.08 \%$ & $0.14 \%$ & $0.50 \%$ & & \\
\hline
\end{tabular}


Table 5 (continued)

Out-of-Sample Global Default Risk Portfolios

\begin{tabular}{|c|c|c|c|c|c|c|c|c|c|c|}
\hline & & \multicolumn{9}{|c|}{ Deciles } \\
\hline & & 1 & 2 & $3-4$ & $5-6$ & $7-8$ & 9 & 10 & Q5-Q1 & P10-P1 \\
\hline \multicolumn{11}{|l|}{ Panel B: C14 Countries } \\
\hline \multirow[t]{4}{*}{ Mean excess return } & vw & -2.14 & -3.12 & 1.74 & 2.56 & 4.99 & 10.01 & 11.12 & $13.42 * * *$ & $13.26 * *$ \\
\hline & & {$[-0.42]$} & {$[-0.49]$} & {$[0.30]$} & {$[0.43]$} & {$[0.76]$} & [1.39] & [1.33] & [3.03] & [2.34] \\
\hline & ew & 4.85 & 3.21 & 5.52 & 6.98 & 9.07 & 10.37 & $17.67 * *$ & $9.99 * * *$ & $12.82 * * *$ \\
\hline & & {$[0.85]$} & {$[0.53]$} & {$[0.83]$} & {$[0.97]$} & [1.21] & {$[1.36]$} & {$[2.06]$} & {$[2.66]$} & {$[2.72]$} \\
\hline \multirow[t]{4}{*}{ CAPM alpha } & vw & $-4.87 * *$ & $-6.53 * * *$ & $-1.95 * *$ & -1.25 & 0.93 & $5.82 *$ & 6.82 & $12.26 * * *$ & $11.69 * *$ \\
\hline & & {$[-2.15]$} & {$[-2.98]$} & {$[2.12]$} & {$[-1.15]$} & {$[0.52]$} & [1.91] & {$[1.46]$} & [2.83] & {$[2.24]$} \\
\hline & ew & 2.27 & 0.10 & 1.76 & 2.94 & $5.03 *$ & $6.42 * *$ & $13.68 * * *$ & $8.86 * * *$ & $11.41 * * *$ \\
\hline & & {$[0.66]$} & {$[0.03]$} & {$[0.63]$} & [1.05] & [1.69] & [2.07] & {$[2.85]$} & {$[2.88]$} & {$[2.80]$} \\
\hline \multirow[t]{4}{*}{ FFC alpha } & vw & $-3.31 * *$ & $-6.47 * * *$ & 0.23 & -0.50 & -0.84 & 1.25 & 5.23 & $7.86 * * *$ & $8.54 * *$ \\
\hline & & {$[-2.38]$} & {$[-3.84]$} & {$[0.22]$} & {$[-0.41]$} & {$[-0.45]$} & {$[0.57]$} & {$[1.30]$} & {$[2.80]$} & {$[2.02]$} \\
\hline & ew & 0.62 & -1.34 & 1.12 & 1.98 & $3.46 *$ & $4.91 * *$ & $13.22 * * *$ & $9.43 * * *$ & $12.60 * * *$ \\
\hline & & {$[0.26]$} & {$[-0.58]$} & {$[0.64]$} & [1.02] & {$[1.72]$} & {$[2.44]$} & {$[4.30]$} & [3.44] & [3.78] \\
\hline average \# of firms & & 1028 & 1028 & 2056 & 2056 & 2056 & 1028 & 1028 & & \\
\hline average sigma & & 0.39 & 0.44 & 0.48 & 0.51 & 0.55 & 0.60 & 0.72 & & \\
\hline average RSIZE & & -9.18 & -9.16 & -9.01 & -9.24 & -9.78 & -10.44 & -11.17 & & \\
\hline average $\mathrm{CHS}$ & & $0.01 \%$ & $0.01 \%$ & $0.02 \%$ & $0.04 \%$ & $0.08 \%$ & $0.13 \%$ & $0.52 \%$ & & \\
\hline
\end{tabular}




\section{Table 6}

\section{Robustness Tests}

This table reports the results of three robustness tests regarding data filters, and the beginning of the portfolio holding period. Results are reported only for the extreme quintile CHS-sorted stock portfolios (Q1 and Q5) and the spread strategy Q5-Q1 that is long the quintile portfolio with the highest default risk stocks (Q5) and short the quintile portfolio with the lowest default risk stocks (Q1). The average excess portfolio returns are annualized and bolded; their associated t-statistics are in square brackets. We construct these portfolios for stocks in the C6 countries (Australia, Canada, France, Germany, Japan and the United Kingdom; Panel A) and for stocks in the C14 countries (the C6 countries plus Denmark, Finland, Hong Kong, New Zealand, Portugal, Spain, Sweden and Taiwan; Panel B). Returns are expressed in USD terms in excess of the USD risk-free rate. Returns are reported for both value-weighted (vw) and equally-weighted (ew) portfolios. The first robustness test ("Return of Defaulting Stocks=-100\%") repeats the analysis of Table 5 setting the returns of filing firms to $-100 \%$ during their filing month. The second robustness test ("Additional Data Filters") repeats the analysis of Table 5 excluding in addition stocks with a zero ex-dividend monthly return and stocks with incomplete data on the market and accounting variables used in the LOGIT model in the prior 12 months. The third robustness test ("No Gap Between Formation \& Holding Period") repeats the analysis of Table 5 leaving no gap between the portfolio formation month (i.e., December of year $t-1$ ) and the beginning of the holding period, which now becomes January of year $t$. ***,** and $*$ denote statistical significance at $1 \%, 5 \%$ and $10 \%$ levels, respectively.

\begin{tabular}{|c|c|c|c|c|c|c|}
\hline \multirow[b]{2}{*}{ Modifications } & \multicolumn{3}{|c|}{ Value-weighted Portfolios } & \multicolumn{3}{|c|}{ Equally-weighted Portfolios } \\
\hline & Q1 & Q5 & Q5-Q1 & Q1 & Q5 & Q5-Q1 \\
\hline \multicolumn{7}{|l|}{ Panel A: C6 Countries } \\
\hline \multirow[t]{2}{*}{ Return of Defaulting Stocks $=-100 \%$} & -2.93 & 10.83 & $13.76 * * *$ & 3.87 & 12.86 & $8.99 * *$ \\
\hline & {$[-0.52]$} & [1.42] & {$[2.70]$} & {$[0.63]$} & {$[1.60]$} & {$[2.13]$} \\
\hline \multirow[t]{2}{*}{ Additional Data Filters } & 0.45 & 11.53 & $11.08 * *$ & 6.08 & $15.62 *$ & $9.54 * *$ \\
\hline & {$[0.09]$} & {$[1.44]$} & {$[2.32]$} & {$[1.00]$} & {$[1.87]$} & {$[2.11]$} \\
\hline \multirow[t]{2}{*}{ No Gap Between Formation \& Holding Period } & -3.75 & 11.66 & $15.41 * * *$ & 3.96 & $14.67 *$ & $10.71 * *$ \\
\hline & {$[-0.65]$} & {$[1.53]$} & {$[2.80]$} & {$[0.63]$} & {$[1.85]$} & {$[2.45]$} \\
\hline \multicolumn{7}{|l|}{ Panel B: C14 Countries } \\
\hline \multirow[t]{2}{*}{ Return of Defaulting Stocks $=-100 \%$} & -2.56 & 10.73 & $13.29 * * *$ & 3.97 & 12.86 & $8.89 * *$ \\
\hline & {$[-0.45]$} & {$[1.43]$} & {$[3.00]$} & [0.68] & {$[1.61]$} & {$[2.36]$} \\
\hline \multirow[t]{2}{*}{ Additional Data Filters } & 0.58 & 11.76 & $11.18 * * *$ & 6.32 & $15.98 *$ & $9.66 * *$ \\
\hline & {$[0.12]$} & {$[1.48]$} & {$[2.60]$} & [1.09] & [1.93] & {$[2.36]$} \\
\hline \multirow[t]{2}{*}{ No Gap Between Formation \& Holding Period } & -3.00 & 11.57 & $14.57 * * *$ & 4.10 & $14.59 *$ & $10.49 * * *$ \\
\hline & {$[-0.53]$} & [1.57] & [3.08] & [0.69] & {$[1.86]$} & [2.79] \\
\hline
\end{tabular}


Table 7

\section{Fama-MacBeth Regressions}

This table reports the results from Fama-MacBeth regressions on the relation between Campbell et al.'s (2008, CHS) default risk measure and subsequent stock returns. For each month of our sample we run cross-sectional regressions of excess stock returns on lagged CHS estimates and a set of firm characteristics that are also lagged. These include beta, log size, book-to-market value ratio (B/M), prior year stock return (MOMENTUM), prior month stock return (REVERSAL), PRICE, SIGMA, NIMTA, TLMTA and CASHMTA. Each firm characteristic is normalized by its standard deviation. Beta has been calculated using past 60 months' stock returns. Models 5 and 6 include country dummies. The coefficients are reported as time-series averages of the estimates from the cross-sectional regressions. The t-statistics, which are reported in brackets, are based on the Newey-West heteroskedasticity and autocorrelation consistent standard errors. $* * *, * *$ and $*$ denote statistical significance at $1 \%, 5 \%$ and $10 \%$ levels, respectively.

\begin{tabular}{|c|c|c|c|c|c|c|}
\hline & Model 1 & Model 2 & Model 3 & Model 4 & Model 5 & Model 6 \\
\hline$\overline{\mathrm{CHS}}$ & $\begin{array}{l}0.0086 * * * \\
{[7.23]}\end{array}$ & $\begin{array}{l}0.0047^{* * *} \\
{[4.60]}\end{array}$ & $\begin{array}{l}0.0036 * * * \\
{[3.60]}\end{array}$ & $\begin{array}{l}\mathbf{0 . 0 0 4 8} * * * \\
{[5.05]}\end{array}$ & $\begin{array}{l}0.0084 * * * \\
{[7.20]}\end{array}$ & $\begin{array}{c}0.0048 * * * \\
{[5.34]}\end{array}$ \\
\hline BETA & - & $\begin{array}{r}0.0002 \\
{[0.11]}\end{array}$ & $\begin{array}{r}-0.0012 \\
{[-1.01]}\end{array}$ & $\begin{array}{r}-0.0006 \\
{[-0.52]}\end{array}$ & - & $\begin{array}{r}-0.0007 \\
{[-0.67]}\end{array}$ \\
\hline LN(MV) & - & $\begin{array}{c}-0.0071 * * * \\
{[-5.09]}\end{array}$ & $\begin{array}{c}-0.0044 * * * \\
{[-4.39]}\end{array}$ & $\begin{array}{l}-0.0051 * * * \\
{[-5.94]}\end{array}$ & - & $\begin{array}{l}-0.0016 * * \\
{[-2.10]}\end{array}$ \\
\hline $\mathrm{B} / \mathrm{M}$ & - & $\begin{array}{c}0.0016 * \\
{[1.69]}\end{array}$ & $\begin{array}{c}0.0015 * \\
{[1.73]}\end{array}$ & $\begin{array}{r}0.0011 \\
{[1.45]}\end{array}$ & - & $\begin{array}{c}0.0018 * * \\
{[2.42]}\end{array}$ \\
\hline MOMENTUM & - & - & $\begin{array}{r}0.0011 \\
{[0.78]}\end{array}$ & $\begin{array}{r}0.0021 \\
{[1.53]}\end{array}$ & - & $\begin{array}{r}0.0021 \\
{[1.46]}\end{array}$ \\
\hline REVERSAL & - & - & $\begin{array}{l}-0.0016 * * \\
{[-2.35]}\end{array}$ & $\begin{array}{c}-0.0013 * \\
{[-1.91]}\end{array}$ & - & $\begin{array}{l}-0.0011 * * \\
{[-1.98]}\end{array}$ \\
\hline PRICE & - & - & $\begin{array}{l}-0.0056 * * * \\
{[-3.94]}\end{array}$ & $\begin{array}{l}-0.0064 * * * \\
{[-5.02]}\end{array}$ & - & $\begin{array}{l}-0.0119 * * * \\
{[-10.64]}\end{array}$ \\
\hline SIGMA & - & - & - & $\begin{array}{l}-0.0030 * * * \\
{[-4.54]}\end{array}$ & - & $\begin{array}{l}-0.0033 * * * \\
{[-4.01]}\end{array}$ \\
\hline NIMTA & - & - & - & $\begin{array}{c}0.0017 * * \\
{[1.99]}\end{array}$ & - & $\begin{array}{c}0.0020 * * * \\
{[3.19]}\end{array}$ \\
\hline TLMTA & - & - & - & $\begin{array}{r}0.0013 \\
{[1.06]}\end{array}$ & - & $\begin{array}{r}0.0004 \\
{[0.51]}\end{array}$ \\
\hline CASHMTA & - & - & - & $\begin{array}{l}0.0039 * * * \\
{[4.05]}\end{array}$ & - & $\begin{array}{l}0.0031 * * * \\
{[4.27]}\end{array}$ \\
\hline CONSTANT & $\begin{array}{r}0.0063 \\
{[1.07]} \\
\end{array}$ & $\begin{array}{l}0.0249 * * * \\
{[3.92]}\end{array}$ & $\begin{array}{l}0.0232 * * * \\
{[3.81]}\end{array}$ & $\begin{array}{l}0.0232 * * * \\
{[3.00]}\end{array}$ & $\begin{array}{r}0.0108 \\
{[1.18]} \\
\end{array}$ & $\begin{array}{l}0.0134 * * \\
{[2.00]}\end{array}$ \\
\hline Country Dummies & No & No & No & No & Yes & Yes \\
\hline Observations & $1,928,527$ & $1,444,725$ & $1,436,565$ & $1,435,710$ & $1,928,527$ & $1,435,710$ \\
\hline
\end{tabular}




\section{Table 8}

\section{Comparison of CHS and MDD-Sorted Portfolio Returns}

This table reports average excess returns for portfolios sorted on the basis of out-of-sample (OOS) estimates of the Campbell et al. (2008, CHS) default risk measure or, alternatively, estimates of Merton's (1974) Distance-to-Default measure (MDD). We construct these portfolios for stocks in the C6 countries (Australia, Canada, France, Germany, Japan and the U.K.; Panel A) and the C14 countries (the C6 countries plus Denmark, Finland, Hong Kong, New Zealand, Portugal, Spain, Sweden and Taiwan; Panel B). The OOS CHS measures are recursively estimated as described in Section 3 and the caption of Table 5. We follow the methodology of Vassalou and Xing (2004) to estimate MDD for each firm in our sample. At the end of December of year $t$ - 1 , we sort stocks in ascending order on the basis of their OOS CHS or, alternatively, on the basis of their OOS MDD estimates and allocate them into decile and quintile portfolios. We form the spread strategy Q5-Q1 that is long the quintile portfolio with the highest default risk stocks (Q5) and short the quintile portfolio with the lowest default risk stocks (Q1). We also form the spread strategy P10-P1 that is long the decile portfolio with the highest default risk stocks (P10) and short the decile portfolio with the lowest default risk stocks (P1). We only consider stocks for which both default risk proxies are available. We exclude stocks whose price or market capitalization is below the $5^{\text {th }}$ percentile of the corresponding country-month distribution at the portfolio formation date. Portfolios are held from February of year $t$ to January of year $t+1$, at which point they are rebalanced, allowing for a one-month gap between the portfolio formation date and the beginning of the holding period. Returns are calculated in U.S. dollar terms and they are reported for both value-weighted (vw) and equally-weighted (ew) portfolios. Average excess portfolio returns are annualized and bolded; their associated t-statistics are reported in square brackets. The lower part of each panel reports the average number of firms per portfolio. For the MDD-sorted portfolios, it also reports stocks' average standard deviation of returns (SIGMA), their average log relative size (RSIZE) and their average OOS CHS default risk estimate. The examined period is $2000-2014 . * * *$, ** and * denote statistical significance at $1 \%, 5 \%$ and $10 \%$ levels, respectively.

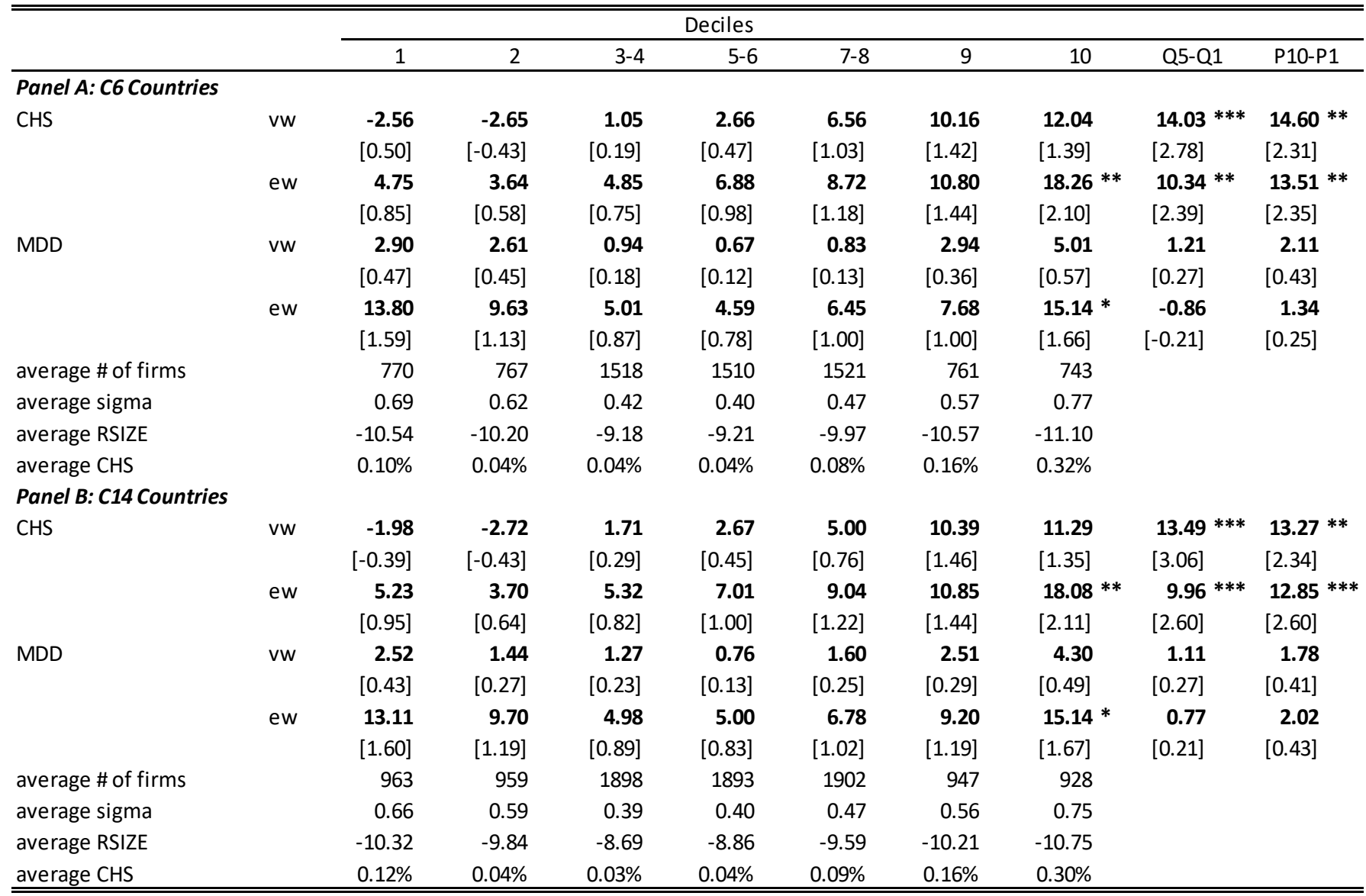


Table 9

\section{Double-Sorted Portfolios}

This table reports average excess returns for double-sorted portfolios on the basis of out-of-sample (OOS) estimates of the Campbell et al. (2008, CHS) default risk measure and each of the following country/firm characteristics: $(i)$ RENEGOTIATION FAILURE, which is an index that summarizes a number of characteristics of debt enforcement procedures that protect creditors from shareholders' strategic default (see Djankov et al., 2008, and Favara et al., 2012, for details), (ii) CREDITOR RECOVERY RATE, which is an inverse measure of the shareholders' benefits to engage in strategic default. In particular, this index takes into account not only the order in which secured creditors are paid, but also the overall estimated costs of the insolvency procedure as well as its duration, and (iii) TANGIBILITY, which is the (firm-level) ratio of property, plant and equipment to total assets. Panel A reports results based on value-weighted global portfolio returns whereas Panel B reports results based on equal-weighted global portfolio returns. The OOS CHS default risk measures are recursively estimated as described in Section 3 and the caption of Table 5. We sort stocks into ascending order according to their OOS CHS default risk estimates in December of year $t-1$ and allocate them into tercile portfolios (T1 to T3), and we also independently sort stocks into ascending order according to the value of each country/firm characteristic in December of year $t-1$ and allocate them into tercile portfolios (Low, Medium, High). The intersection of these two classifications yields the double-sorted portfolios. Portfolios are held from February of year $t$ to January of year $t+1$, at which point they are rebalanced, allowing for a one month gap between the portfolio formation date and the beginning of the holding period. Results are reported only for the highest and the lowest default risk tercile portfolios (T3 and T1, respectively) within the High or the Low classification for each country/firm characteristic, respectively. Moreover, we report the average excess return for the spread strategy T3-T1 within the High or Low classification. For comparison, column ALL reports the returns for the tercile portfolios T3 and T1 from univariate sorts according to OOS CHS default risk estimates. Returns are calculated in U.S. dollar. Average excess portfolio returns are annualized and bolded; their associated t-statistics are reported in square brackets. The examined period is $2000-2014$. $* * * * *$ and $*$ denote statistical significance at $1 \%, 5 \%$ and $10 \%$ levels, respectively.

\begin{tabular}{|c|c|c|c|c|c|c|c|}
\hline \multirow[b]{2}{*}{$\mathrm{CHS}$} & \multirow[b]{2}{*}{ ALL } & \multicolumn{2}{|c|}{$\begin{array}{c}\text { RENEGOTIATION } \\
\text { FAILURE }\end{array}$} & \multicolumn{2}{|c|}{$\begin{array}{c}\text { CREDITOR } \\
\text { RECOVERY RATE }\end{array}$} & \multicolumn{2}{|c|}{$\begin{array}{c}\text { TANGIBILITY OF } \\
\text { ASSETS }\end{array}$} \\
\hline & & High & Low & High & Low & High & Low \\
\hline \multicolumn{8}{|c|}{ Panel A: Value-weighted Global Portfolios Based on C14 Countries } \\
\hline \multirow[t]{2}{*}{ T3 } & 7.56 & 8.02 & 3.03 & 6.41 & 6.08 & 10.85 & 3.68 \\
\hline & {$[1.12]$} & {$[1.04]$} & {$[0.44]$} & {$[0.91]$} & {$[0.82]$} & [1.34] & {$[0.42]$} \\
\hline \multirow[t]{2}{*}{$\mathrm{T} 1$} & -1.71 & 0.09 & 0.87 & -3.42 & 2.27 & -3.92 & -3.77 \\
\hline & {$[-0.29]$} & {$[0.01]$} & [0.18] & {$[-0.58]$} & [0.39] & {$[-0.58]$} & {$[-0.51]$} \\
\hline \multirow[t]{2}{*}{ Spread (T3-T1) } & $9.27 * * *$ & $7.93 *$ & 2.16 & $9.83 * *$ & 3.81 & $14.77 * * *$ & $7.45 * *$ \\
\hline & {$[2.70]$} & {$[1.87]$} & {$[0.78]$} & [2.09] & [1.33] & [3.65] & {$[2.11]$} \\
\hline \multicolumn{8}{|c|}{ Panel B: Equally-weighted Global Portfolios Based on C14 Countries } \\
\hline \multirow[t]{2}{*}{ T3 } & 12.50 & 14.15 & 7.94 & 12.73 & 11.39 & 18.18 & 8.30 \\
\hline & [1.59] & [1.58] & [1.14] & [1.60] & [1.42] & [0.82] & {$[0.82]$} \\
\hline \multirow[t]{2}{*}{$\mathrm{T} 1$} & 4.50 & 3.96 & 5.42 & 3.48 & 6.61 & 5.34 & 3.39 \\
\hline & {$[0.75]$} & {$[0.47]$} & [1.10] & [0.56] & [0.95] & [0.82] & [0.41] \\
\hline \multirow[t]{2}{*}{ Spread (T3-T1) } & $8.00 * * *$ & $10.19 * * *$ & 2.52 & $9.25 * *$ & 4.78 & $12.84 * * *$ & 4.91 \\
\hline & [2.65] & {$[4.05]$} & [0.73] & [2.39] & [1.51] & [3.53] & [1.24] \\
\hline
\end{tabular}




\section{Figure 1}

\section{Default Risk Portfolios' Factor Loadings}

This figure presents the market, size (SMB), value (HML) and momentum (MOM) factor loadings (betas) of value-weighted portfolios sorted on the basis of the out-of-sample (OOS) Campbell et al. (2008, CHS) default risk estimates. These betas are estimated from full-sample regressions of each excess portfolio return on the excess market return and the SMB, HML and MOM factor returns according to the four-factor FamaFrench-Carhart (FFC) asset pricing model. The sample period is 2000-2014. Factor loadings are presented for portfolios of stocks from the C6 countries (Australia, Canada, France, Germany, Japan and the U.K.) and the C14 countries (the C6 countries plus Denmark, Finland, Hong Kong, New Zealand, Portugal, Spain, Sweden and Taiwan). To estimate OOS CHS default risk estimates, a LOGIT model is recursively run for each of the C6 countries; see Section 3 and the caption of Table 5. For the countries that feature too few bankruptcies, we run recursively a LOGIT model for each bankruptcy law regime, see caption of Table 5 for details.
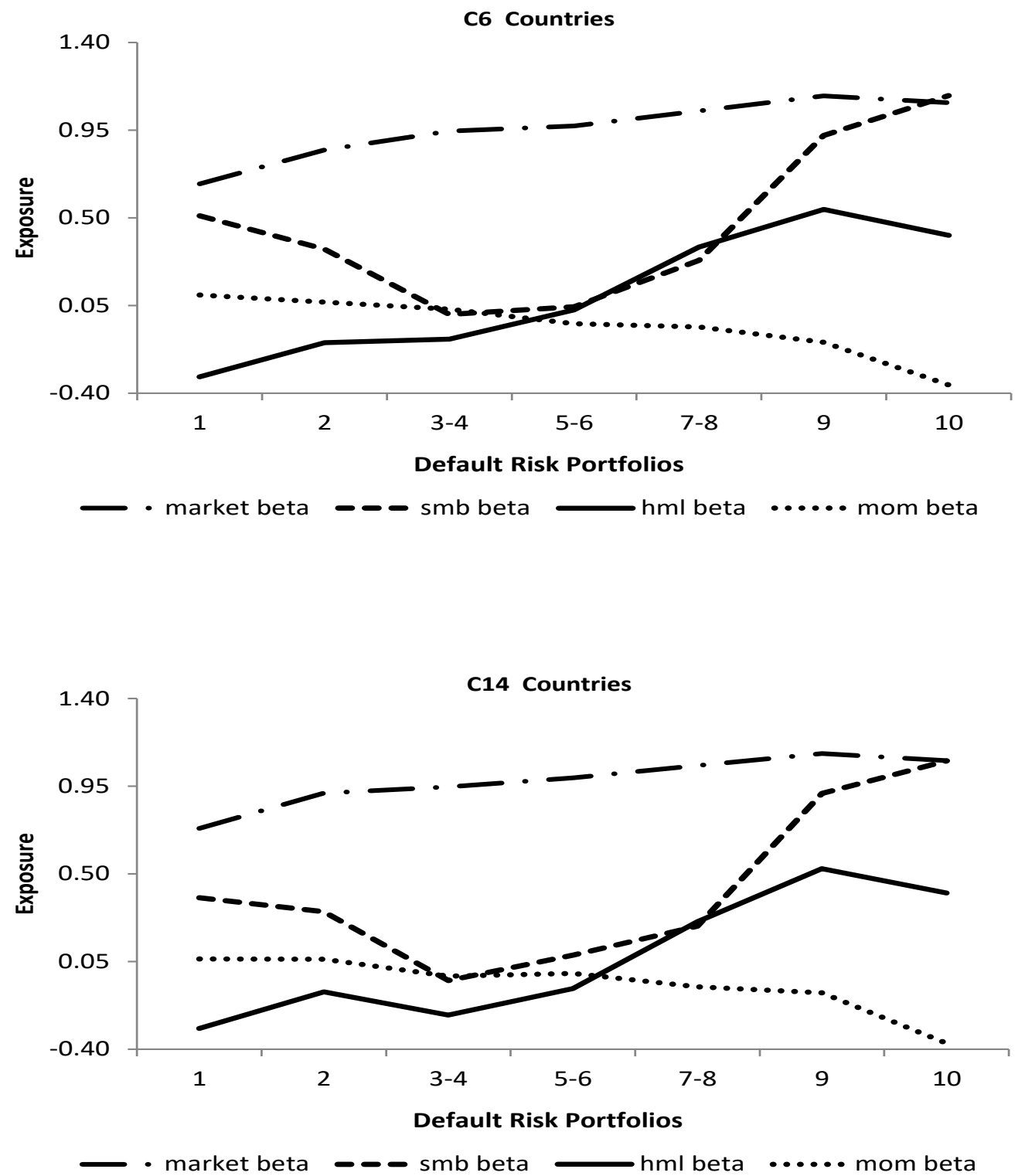


\section{Figure 2}

\section{Profitability of Default Risk Spread Strategies}

This figure shows the profitability of distress risk spread strategies that are long the decile portfolio with the highest default risk stocks (P10) and short the decile portfolio with the lowest default risk stocks (P1), as classified on the basis of the Campbell et al. (2008, CHS) default risk estimates. We use as a portfolio sorting variable out-of-sample (OOS) CHS default risk values, estimated recursively using LOGIT models, as described in the caption of Table 5, and the examined period is 2000-2014. Portfolios P10 and P1 are formed at the end of each December of year $t-1$ and they are held from February of year $t$ to January of year $t+1$, at which point they are rebalanced. Returns are calculated in U.S. dollar terms and they are reported for both value-weighted (vw) and equally-weighted (ew) portfolios. Results are reported for the C6 countries (Australia, Canada, France, Germany, Japan and the U.K.) and the C14 countries (the C6 countries plus Denmark, Finland, Hong Kong, New Zealand, Portugal, Spain, Sweden and Taiwan). The shaded areas in the graphs indicate OECD-defined recession periods, where the light grey indicates that 4-8 of our sample countries are in a recession, the moderately dark grey that 8-12 are in a recession, and the dark grey that more than 12 are in a recession.

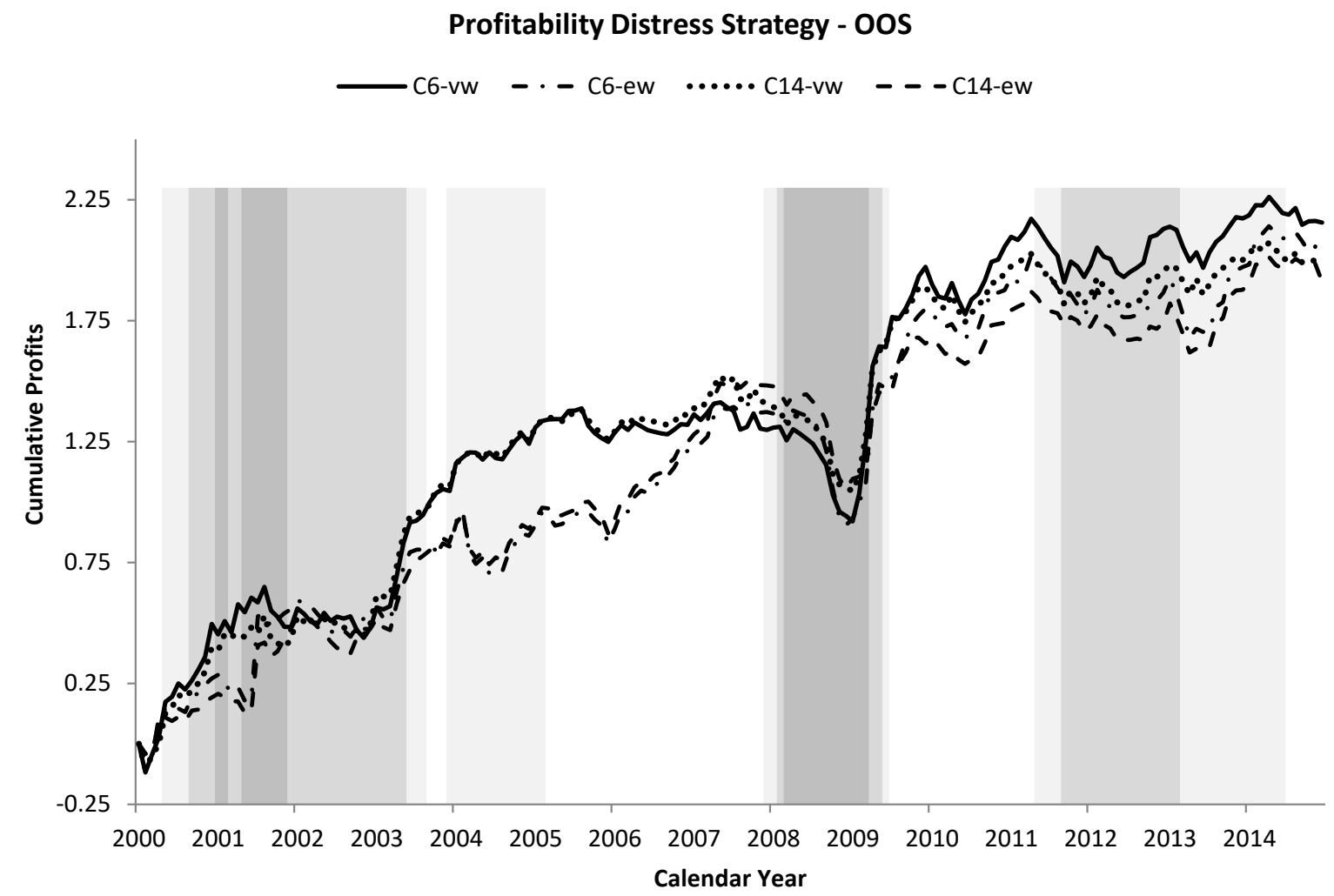

